\title{
WestVirginiaUniversity
}

THE RESEARCH REPOSITORY @ WVU

Graduate Theses, Dissertations, and Problem Reports

2020

\section{The Pattern of Odontogenic Referred Pain}

James J. Poulos

West Virginia University, jp0087@mix.wvu.edu

Follow this and additional works at: https://researchrepository.wvu.edu/etd

Part of the Endodontics and Endodontology Commons

\section{Recommended Citation}

Poulos, James J., "The Pattern of Odontogenic Referred Pain" (2020). Graduate Theses, Dissertations, and Problem Reports. 7970.

https://researchrepository.wvu.edu/etd/7970

This Thesis is protected by copyright and/or related rights. It has been brought to you by the The Research Repository @ WVU with permission from the rights-holder(s). You are free to use this Thesis in any way that is permitted by the copyright and related rights legislation that applies to your use. For other uses you must obtain permission from the rights-holder(s) directly, unless additional rights are indicated by a Creative Commons license in the record and/ or on the work itself. This Thesis has been accepted for inclusion in WVU Graduate Theses, Dissertations, and Problem Reports collection by an authorized administrator of The Research Repository @ WVU. For more information, please contact researchrepository@mail.wvu.edu. 


\title{
The Pattern of Odontogenic Referred Pain
}

\author{
James J. Poulos, DDS
}

Thesis submitted to the School of Dentistry at West Virginia University in partial fulfillment of the requirements for the degree of Master of Science in Endodontics

Christina B. DeBiase, MA, EdD, Chair

Daniel W. McNeil, PhD

Jerry Bouquot, DDS, MSD

Department of Endodontics

Morgantown, WV

2020

Keywords: endodontics, referred, heat map, diagnosis, pain, molar, premolar, anterior teeth

Copyright 2020 James J. Poulos, DDS 


\section{ABSTRACT \\ The Pattern of Odontogenic Referred Pain}

\section{James J. Poulos, DDS}

Background: Referred odontogenic pain (RP) is a phenomenon that is seen regularly in dentistry and it is not extensively understood. It can make formulating a proper diagnosis difficult and its presence can lead to inappropriate treatment.

Methods: 250 patients experiencing odontogenic pain within the dental clinics of West Virginia University were surveyed. The survey inquired about the patient's biographical information, medical history, characteristics of the pain, the presence and location of RP, and the psychosocial effects of the pain. Additionally, the endodontic diagnosis of the offending tooth was determined by a member of the endodontic department. The collected data was then statistically analyzed via chi-square test, binary logistic regression, t-test, and ANOVA.

Results: Statistically significant associations were developed with the presence of RP and a diagnosis of irreversible pulpitis (IP), as compared with pulp necrosis (PN), and the female gender, as compared with the male gender. Overall, $45.6 \%$ (114/250) of subjects experienced RP. Among those with RP, $68.4 \%$ had a pulpal diagnosis of IP and $30.7 \%$ had a pulpal diagnosis of PN. Subjects with RP reported an increased effect on their activity, sleep, mood, and stress on a DVPRS pain scale. Female subjects also reported an increased effect on activity, mood, and stress. Heat maps were generated for each tooth sextant.

Conclusions: RP is more often associated with a diagnosis of IP and the female gender (as opposed to PN and the male gender, respectively). Increased psychosocial effects were found in subjects experiencing RP. 


\section{Dedication}

I would like to dedicate this thesis and my entire education to my wife, Stavroula, and my parents, John and Betty.

To Mom and Dad, you have supported me through my entire life, and I cannot begin to thank you enough. You are the best role models that a son could ask for and I would not be a fraction of the man I am today without you.

To my loving wife Stavroula, thank you so much for your support, patience, and love throughout our lives together and my academic career. We are finally at the end of our long journey and I am so excited to start the next chapter of our lives together in Columbus. You are an unbelievably strong woman and an inspiration.

Thank you and I love you. 


\section{Acknowledgements}

A special thank you to everyone below who helped with many aspects of my thesis. Your assistance and guidance was invaluable and I cannot begin to thank you enough.

- Dr. Christina DeBiase

○ Associate Dean for Academic Affairs, Co-principal investigator, chair of my committee, provided guidance and advice as to how to develop and conduct the project

- Dr. Daniel W. McNeil

○ Professor in Clinical Psychology, faculty member in the Departments of Psychology, and Dental Practice \& Rural Health, member of my committee, provided guidance and advice as to how to develop and conduct the project

- Dr. Jerry Bouquot

- Clinical Professor in Oral Pathology, member of my committee, provided guidance and advice as to how to develop and conduct the project

- Dr. Mark Byron

○ Director of the Post-Doctoral Endodontic Program, assisted in administering surveys and establishing the subject's pulpal diagnosis, provided guidance and advice as to how to develop and conduct the project

- Dr. Samuel Dorn

- Chair of the Department of Endodontics, assisted in administering surveys and establishing the subject's pulpal diagnosis, provided guidance and advice as to how to develop and conduct the project 
- Dr. R. Constance Wiener

- Associate Professor, assisted with data analysis, provided guidance and advice as to how to develop and conduct the project

- Christopher Waters

- Research Labs Director, assisted with data analysis, provided guidance and advice as to how to develop and conduct the project

- Dr. Bryan Whitaker

- Chair of Diagnostic Sciences, assisted in administering surveys and establishing the subject's pulpal diagnosis

- Dr. L. Keith Hildebrand

○ Director of the Pre-Doctoral Endodontic Program, assisted in administering surveys and establishing the subject's pulpal diagnosis, provided guidance and advice as to how to develop and conduct the project

- Dr. Michelle Romeo

- Endodontic co-resident, assisted in administering surveys and establishing the subject's pulpal diagnosis

- Dr. D. Cade Brawley

- Endodontic co-resident, assisted in administering surveys and establishing the subject's pulpal diagnosis

- Dr. Mehran Malakpour

- Endodontic co-resident, assisted in administering surveys and establishing the subject's pulpal diagnosis 
- Dr. Asmi Shah

- Endodontic co-resident, assisted in administering surveys and establishing the subject's pulpal diagnosis 
Table of Contents

\section{Chapter 1}

Section I: Introduction............................................................. p. 1

Section II: Literature Review.................................................. p. 6

\section{Chapter 2}

Section III: Methods and Materials.................................................. p. 13

\section{Chapter 3}

Section IV: Results............................................................ p. 16

\section{Chapter 4}

Section V: Discussion.......................................................... p. 34

Section VI: Conclusion.......................................................... 36

References............................................................................. p. 38

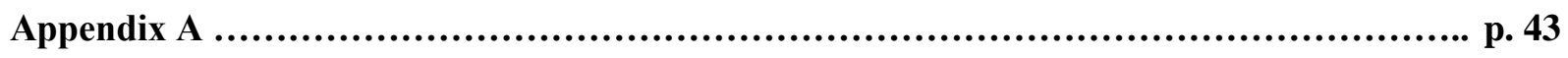




\section{Tables}

- Table 1 - p. 17 - frequency and percentages of the subjects' gender

- Table 2 - p. 18 - frequency and percentages of the subjects' age

- Table 3 - p. 19 - frequency and percentages of the subjects' race/ethnicity

- Table 4 - p. 21 - Incidence of referred pain for pulp necrosis, irreversible pulpitis and the other diagnosis groups

- Table 5 - p. 22 - mean values (with standard deviation) on the DVPRS scale for how the subject's odontogenic pain has affected their activity, sleep, mood, and stress in the last 24 hours for different diagnosis and the presence or absence of referred pain

- Table 6 - p. 22 - mean values (with standard deviation) on the DVPRS scale for how the subject's odontogenic pain has affected their activity, sleep, mood, and stress in the last 24 hours with the male and female gender groups 


\section{Figures}

- Figure 1 - p. 14 - blank face where patients mark areas of referred pain

- Figure 2 - p. 17 - bar chart of referred pain vs. gender

- Figure 3 - p. 18 - bar chart of referred pain vs. age

- $\quad$ Figure 4 - p. 19 - bar chart of referred pain vs. race/ethnicity

- Figure 5 - p. 20 - bar chart of endodontic diagnosis frequencies

- Figure 6 - p. 20 - bar chart of referred pain vs. endodontic diagnosis

- $\quad$ Figure 7 - p. 23 - bar chart of referred pain's effect on activity

- $\quad$ Figure 8 - p. 23 - bar chart of referred pain's effect on mood

- $\quad$ Figure 9 - p. 24 - bar chart of referred pain's effect on sleep

- Figure 10 - p. 24 - bar chart of referred pain's effect on stress

- Figure 11 - p. 25 - bar chart of pulpal diagnosis vs. the pain's effect on activity

- Figure 12 - p. 25 - bar chart of pulpal diagnosis vs. the pain's effect on mood

- Figure 13 - p. 26 - bar chart of pulpal diagnosis vs. the pain's effect on sleep

- Figure 14 - p. 26 - bar chart of pulpal diagnosis vs. the pain's effect on stress

- Figure 15 - p. 27 - bar chart of referred pain vs. each dental sextant

- Figure 16 - p. 28 - heat map associated with maxillary molars

- $\quad$ Figure 17 - p. 29 - heat map associated with maxillary premolars

- $\quad$ Figure 18 - p. 30 - heat map associated with maxillary anterior teeth

- Figure 19 - p. 31 - heat map associated with mandibular molars

- $\quad$ Figure 20 - p. 32 - heat map associated with mandibular premolars

- Figure 21 - p. 33 - heat map associated with mandibular anterior teeth 


\section{Chapter 1.}

\section{Introduction}

Referred pain is a phenomenon experienced by countless individuals both as patients and providers. Dental professionals struggle to recognize and diagnose referred pain daily. For example, if a patient reports to a clinic on an emergency basis complaining of pain of the left lower dental quadrant that is referring to the ear, a dental professional that is not familiar with referred pain and its relation to facial dermatomes may have a hard time pinpointing the tooth that is the source of the problem. According to previous research, mandibular posterior teeth have a propensity to cause pain to refer to the ipsilateral mandibular ramus and ear. ${ }^{1-6}$

Additionally, if a patient states that his or her pain is coming from a mandibular tooth, but the teeth in that region appear to be healthy, it is possible that the pain is referring from the maxillary teeth via the trigeminal ganglion. Knowing and remembering pain referral patterns and any predisposition to a patient experiencing referred pain, can aid dental professionals when patients inevitably present with difficult diagnoses.

During their education, dental students are taught to recognize pain and how to properly diagnose painful teeth. Referred pain is a topic that is mentioned and briefly explained, with little attention to its more complicated and specific diagnostic features. This understanding can promote proper diagnoses, allowing patients to be treated in a more appropriate and timely manner.

A patient exhibiting regional pain with no clear dental etiology is often given a diagnosis of clenching or improper occlusion. While these may contribute to the problem, they may not be the most significant cause or may be only a consequence of the referred pain. This can lead to 
inappropriate dental therapy or, more frequently, lead to management by a "wait and see" approach, i.e. wait for the pain to localize to a single tooth. While this can be an effective method of identifying the primary etiology of dental pain, it is not always necessary.

Remembering referred pain patterns may be more helpful in forming a proper and more accurate diagnosis. This research investigation attempts to provide a learning tool to help students and practitioners learn and apply the intricacies and patterns of such pain.

\section{Statement of Problem}

Past studies ${ }^{1-6}$ have investigated the pattern of referred pain from maxillary and mandibular molars, but the pain referral patterns of maxillary and mandibular anterior teeth and premolars have yet to be defined. Additionally, the relationship between a certain endodontic diagnosis and referred pain has only been theorized, not scientifically proven.

\section{Purpose and Significance of the Study}

The aims of this study are to map the location and determine a pattern of referred odontogenic pain from each dental region (maxillary molar, mandibular molar, maxillary premolar, mandibular premolar, maxillary anterior, mandibular anterior). This study will also investigate the rate of incidence of dental referred pain, if certain dental diagnoses cause a higher incidence of referred pain, and whether any characteristics (such as gender or race) predispose a patient to referred pain.

Wright mentioned in his publication ${ }^{7}$ "it would be helpful for dental practitioners to have drawings delineating regions with a high probability for a patient's referred pain source." $\mathrm{He}$ palpated various muscles (imitating a source of pain) and determined which other muscles or teeth would receive a referred pain sensation. Similarly, if a patient's source of pain is 
odontogenic, it would be useful to have a map of the pattern of referred odontogenic pain for dental professionals to use on a daily basis.

It is expected that the results of the present investigation can serve as an educational tool for dental students and a practical diagnostic adjunct for practicing dentists. A comprehensive outline of when and where to expect referred pain to occur would be useful. Additionally, if a connection can be made between a specific endodontic diagnosis and referred pain, then a dental practitioner would be able to look for teeth with that diagnosis and find the culprit. This would likely reduce the number of teeth that are endodontically treated that either do not need the treatment or are not the source of the patient's current pain.

\section{Hypothesis}

Null hypothesis: No pattern of odontogenic referred pain exists. There are no gender, racial, or diagnostic predispositions to its incidence.

Alternative hypothesis: There is a pattern involved with odontogenic referred pain, and there are gender, racial, or diagnostic predispositions to its incidence.

\section{Assumptions}

- Generally, referred pain will follow the facial dermatomes

- Referred pain will be more prevalent in patients who are having pain in their molars (maxillary or mandibular) 


\section{Limitations}

- Different endodontic residents/endodontists will be performing the evaluations and testing, leading to a potential for inconsistency among the diagnoses. This will be addressed and minimized by calibrating all clinicians who will be collecting the data.

- Patients may not be completely truthful in their pain reports or may not wish to divulge some of the information on the survey.

- Patients may not be able to describe or localize their pain accurately.

\section{Delimitations}

- Individuals participating in the study must be 18 years of age or older

- Individuals participating in the study must read and sign the consent form

- Only patients who are currently experiencing odontogenic pain will be included in the investigation

- All patients included in the study must be examined by an endodontist or endodontic resident or under the supervision of an endodontist or endodontic resident, all of whom would be calibrated

\section{Definition of Terms}

- Asymptomatic apical periodontitis - Apical diagnosis where the periodontium is inflamed and destroyed as a result of pulpal inflammation and/or necrosis, but periodontal symptoms are not present. ${ }^{8}$

- Convergence (neural) - The occurrence when one postsynaptic cell receives convergent input from a number of different presynaptic cells

- Dermatome - The area of the skin supplied by nerves from a single spinal root 
- Diagnosis - The identification of a disease process

- Innervate - Nerve supply to an organ or body part

- Interneuron - A neuron that transmits impulses between other neurons

- Lamination - Process by which cells are arranged in layers within a tissue

- Myofascial Pain-dysfunction Syndrome: "facial pain with a significant myofascial component" $" 9$

- Neuralgia - Intense pain along a nerve, especially in the head or face

- Normal Apical Tissues - Apical diagnosis where the periodontium is asymptomatic and "radiographically, the lamina dura surrounding the root is intact and the periodontal ligament space is uniform." 8

- Odontogenic - Originates from a tooth

- Periauricular - Of, relating to, occurring in, or the tissues surrounding the external ear

- Pulpalgia - Pain arising from the dental pulp

- Referred pain - Pain felt in a part of the body other than its source

- Ruffini fibers - Mechanoreceptor that senses touch, pressure and vibration

- Symptomatic irreversible pulpitis - Endodontic pulpal diagnosis based on "subjective and objective findings that the vital inflamed pulp is incapable of healing and that root canal treatment is indicated." 8

- Trigger point - "A focus of hyperirritability in a tissue that, when compressed, is locally tender and, if sufficiently hypersensitive, gives rise to referred pain and tenderness.",9 


\section{$\underline{\text { II. Literature Review }}$}

\section{Referred pain: Medical Background}

The phrases "brain freeze" or "ice cream headache" refer to a form of referred pain that occurs regularly in the public. The terms are in reference to a cold stimulus pain (often initiated by consumption of cold water, ice cream, etc.) resulting from aggravated nerves in a person's palate referring to their forehead ${ }^{10}$. The scientific name for this phenomenon is sphenopalatine ganglioneuralgia and it occurs as a result of a nerve response causing rapid dilation and constriction of the blood vessels in the palate, sending this response to the brain ${ }^{11}$.

Another example of referred pain is sciatica. Sciatica leads to back pain and a resultant referred pain that is due to the compression of the nerve root from L1 to L4. This compression causes pain to radiate down the sciatic nerve leading to pain in the patient's leg or foot ${ }^{12}$. Multiple other instances of referred pain have been recorded and researched to help professionals understand when, how, and why referred pain occurs.

\section{Neural anatomy of the six dental zones (maxillary molars, maxillary premolars, maxillary anterior teeth, mandibular molars, mandibular premolars, mandibular anterior teeth) ${ }^{13}$ :}

The trigeminal nerve emerges from the brainstem and becomes the trigeminal ganglion. The trigeminal nerve, ganglion, and its branches are present bilaterally. This ganglion is located within Meckel's cave and yields three branches: ophthalmic nerve $\left(\mathrm{V}_{1}\right)$, maxillary nerve $\left(\mathrm{V}_{2}\right)$, and mandibular nerve $\left(\mathrm{V}_{3}\right)$. The ophthalmic nerve innervates anatomic structures of the eye and the nasal cavity. The maxillary nerve innervates the teeth of the maxillary dental arch and the maxillary sinus. The mandibular nerve innervates the teeth of the mandibular dental arch. 
The maxillary nerve exits the skull via the foramen rotundum and goes to the pterygopalatine fossa where it splits into four branches: posterior superior alveolar nerve, infraorbital nerve, zygomatic nerve, and ganglionic branches to the pterygoid plexus. The posterior superior alveolar nerve innervates the maxillary molars with the exception of the mesiobuccal root of the maxillary first molar. The infraorbital splits into two subsequent nerve branches: anterior superior alveolar nerve and middle superior alveolar nerve. The middle superior alveolar nerve innervates the mesiobuccal root of the maxillary first molar, the maxillary premolars and the medial and lateral aspects of the maxillary sinus. The anterior superior alveolar nerve innervates the maxillary incisors and canines as well as the anterior aspect of the maxillary sinus.

The mandibular nerve exits the skull through the foramen ovale and splits into the anterior and posterior divisions. The anterior division branches into the masseteric nerve, the deep temporal nerves, the buccal nerve, and the lateral pterygoid nerve. The posterior division branches into the auriculotemporal nerve, the lingual nerve, and the inferior alveolar nerve. The inferior alveolar nerve enters the mandibular foramen and terminates as the mental and incisive nerves. The incisive nerve supplies the teeth and periodontal ligaments of the first mandibular premolar and the mandibular incisors and canines. The mental nerve innervates the chin, lower lip, facial gingiva, and the mucosa of the premolars and mandibular anterior teeth. The inferior alveolar nerve innervates all of the ipsilateral mandibular teeth, whether it is through the nerve itself or its subsequent branches. 


\section{Referred Pain: Dental Background and Etiology}

Referred pain can result from non-odontogenic sources to the dentition as well. ${ }^{14}$ According to Travell and Simons ${ }^{9}$, there are trigger zones present in the masseter, temporalis, and anterior belly of the digastric that can refer pain to the dentition. The superior belly of the masseter can refer to maxillary posterior teeth and, in some cases, to the external auditory meatus ${ }^{15}$, and the inferior belly of the masseter was found to refer to mandibular posterior teeth. Various trigger points within the temporalis muscle can lead to pain being referred to the maxillary incisors, premolars or molars, and should be considered when the patient also suffers from a consistent headache. ${ }^{9}$ Additionally, pain originating in the anterior belly of the digastric muscle can lead to pain of the mandibular anterior teeth and their corresponding alveolar ridge. ${ }^{9}$

When examining a patient with non-odontogenic pain, it is important to evaluate and treat the pain accordingly. According to $\mathrm{Nel}^{16}$, occlusal disharmony and faulty dental construction are the two most common causes of myofascial-pain dysfunction syndrome at $35 \%$ and $24 \%$, respectively. Possible treatment modalities include occlusal adjustment, a retainer, orthodontic treatment, a mouthguard, and changed daily habits. Evaluation for referred pain should be performed before any such treatments are rendered

Previous research has determined that the nerve fibers responsible for referred pain are the $\mathrm{C}$ fibers. ${ }^{17}$ These are one of the two different types of nerve fibers present within dental pulp, along with A-delta fibers. According to Bender, ${ }^{17}$ A-delta fibers "evoke a rapid, sharp lancinating pain reaction," while C fibers are responsible for "a slow dull, crawling pain." When patients experience extreme and sharp temperature sensitivities, the A-delta fibers are being excited. On the other hand, when a patient reports a sore or achy sensation, one can infer that the 
C fibers are being excited and it is this type of fiber that is responsible for odontogenic referred pain.

Additionally, convergence appears to be partially responsible for referred pain ${ }^{18-21}$. This occurs when a postsynaptic cell receives input from multiple presynaptic cells within a neuronal network $^{22}$. The caudalis of the trigeminal ganglion is laminated, allowing it to receive multiple sensory inputs through a shared interneuron. The trigeminal nerve has three primary branches and many subsequent branches along which efferent or afferent nerve signals can pass ${ }^{23}$. The theory is that this interneuron sends the pain sensation to a different location from which it was originally received via the multitude of trigeminal nerve branches present, yielding referred $\operatorname{pain}^{19}$.

Ohara et al. ${ }^{24}$ determined that the signaling used in referred pain is with Hsp70-TLR4 neurons through the trigeminal ganglion. This type of neuron leads to referred pain from the tooth pulp to the tongue. It can therefore be inferred that those same neurons could be responsible for other forms of referred pain originating from the dental pulp. This complex type of pain can make forming an appropriate and accurate diagnosis of a tooth exceptionally difficult ${ }^{1,17,25}$.

\section{Clinical Effects and Current Diagnosis of Odontogenic Referred Pain}

Falace et al. ${ }^{26}$ reported that $89.8 \%$ of patients that present for emergency dental treatment exhibit referred pain. If a patient presents complaining about orofacial pain, and a dental professional is having a difficult time localizing the source, some existing techniques can be useful. If a patient is a good historian, they may remember where the pain originated ${ }^{1}$. Although, the patient may also insist the pain is coming from a tooth or area that does not seem to be affected by caries, infection, or pathosis. 
Typically, a dental professional would begin to diagnose the issue by conducting sensibility tests on teeth in the area where the pain is originating. Sensibility testing methods, unfortunately, have a limited effectiveness when the testing is not being conducted in the proper area. In 1968, Friend and Glenwright determined that electric pulp testers can help to localize the tooth from which the pain is originating only $37.2 \%$ of the time, and the location could be narrowed to three teeth $79.5 \%$ of the time ${ }^{27}$. Other methods of sensibility testing include cold and heat tests. When attempting to formulate a diagnosis and origin of the pain, although sensibility testing has limited effectiveness, it can allow the dental professional to eliminate areas where the pain is not occurring.

A concept known as selective anesthesia ${ }^{1}$ can also be employed to narrow the location from which the patient's pain is originating. When a patient is experiencing pain on the left side, but cannot differentiate whether the source is the maxillary or mandibular posterior teeth, the dental professional can anesthetize one of the areas and if the patient's pain dissipates or remains, then the examination can be re-focused accordingly. As areas are eliminated, the source of the pain can eventually be discovered and properly diagnosed ${ }^{28}$.

As previously mentioned, some dental professionals will employ a "wait and see" technique to allow the pain or sensitivity to localize. This approach is based on the idea that when a patient is experiencing referred pain which is not yet sensitive to percussion, the inflammation is localized to the pulp. According to Byers and Maeda ${ }^{29}$, the Ruffini mesencephalic PDL fibers cause the clinical percussion sign (pain or sensitivity associated with percussion of the tooth). If the inflammatory process has yet to yield a percussion sign, then it is considered to be contained within the pulp temporarily. 


\section{Endodontic Diagnoses}

In endodontics, there are two general categories of diagnoses: pulpal and apical. The pulpal diagnosis refers to a condition of the vasculature within the pulp. The apical diagnosis refers to a condition of the bone and periodontium around the apex of the tooth. In the fall of 2013, the American Association of Endodontists (AAE) released a publication on Endodontic Diagnosis $^{8}$, which reviewed historical academic studies ${ }^{30-36}$ and outlined the different diagnoses and their definitions. As mentioned previously, referred pain is thought to be due to inflammatory processes within the pulp that have yet to reach the periapical tissues. By definition, this theory indicates that a patient with referred pain would be experiencing irreversible pulpitis. According to the AAE's publication, inflammation involved in irreversible pulpitis is "incapable of healing" and has "not yet reached the periapical tissues." In terms of an apical diagnosis, if the patient is not experiencing percussion symptoms, then their diagnosis would be either normal apical tissues, or asymptomatic apical periodontitis.

\section{Previously Examined Patterns of Referred Pain}

General odontogenic pain referral patterns documented in the past literature concluded that posterior teeth can refer to the opposite $\operatorname{arch}^{3}$ or the periauricular area, and mandibular posterior teeth are known to cause periauricular referred pain more often than maxillary posterior teeth.

It is also important to keep in mind that multiple sources can contribute to a patient's referred pain ${ }^{4}$. The treatment of referred odontogenic pain includes the identification of a symptom's true source $(\mathrm{s})^{5}$, and appropriate treatment of that tooth whether it be excavation and restoration, root canal treatment, or extraction. 
A current, general guideline of where to look when a patient is experiencing referred facial pain is to follow the dermatomes. According to Cohen's Pathways of the Pulp ${ }^{1}$, the typical referral patterns of deep somatic pain tend to follow peripheral dermatomes ${ }^{37}$ that are affected by the various branches of the trigeminal nerve. The mandibular teeth, which are innervated by cranial nerve V3 (CN V3, mandibular nerve), would theoretically follow the dermatome of $\mathrm{CN}$ V3. Similarly, the maxillary teeth, which are innervated by cranial nerve V2 (CN V2, maxillary nerve), would follow CN V2. However, with the exception of maxillary and mandibular molars ${ }^{6}$, extensive research has yet to be conducted.

Another consideration is that $3 \%$ of TMD patients have their pain occur as a result of referred acute pulpalgia. ${ }^{38}$ Additionally, it has been found that impacted third molars can cause trigger points within masticatory muscles, even when there is an absence of infection. ${ }^{9}$ All of these established characteristics and patterns must be taken into account when diagnosing a patient with referred pain. 


\section{Chapter 2.}

\section{Methods and Materials}

This investigation was done with approval from the Institutional Review Board of West Virginia University. A review of past referred pain literature and a power analysis was conducted to determine the necessary number of subjects to include in the study. The power analysis (alpha $=0.05$, beta $=0.2$, power $=0.8$ ) yielded a minimum sample size of 85 subjects. Two hundred and fifty patients were recruited from West Virginia University's School of Dentistry. More specifically, patients were recruited from the urgent care clinic, dental student clinic, and endodontics clinic within the School of Dentistry. This number was chosen based on the results of the power analysis and methodologies of past investigations. . $^{67,39,40,41}$ Many of the previous studies evaluated approximately 40 patients per region and since this study attempted to evaluate six regions of the dentition (maxillary molars, maxillary premolars, maxillary anterior teeth, mandibular molars, mandibular premolars, and mandibular anterior teeth), 250 subjects was deemed appropriate.

Patient subjects were required to meet the inclusion criteria outlined. The diagnosis was made by an endodontic resident or faculty member, or by a dental student under the supervision of an endodontic resident or faculty member. Each endodontic resident and faculty member received calibration training to ensure that the diagnostic testing was conducted as uniformly as possible. Each patient signed a consent form and was asked to complete a questionnaire with their demographic information (age, gender, and race/ethnicity), and current medications. There was no compensation for participation in this study and refusal to participate in the study did not affect the patient's care in any way. The questionnaire and survey contained a cover page. The subject then completed a form, indicating the various locations where their odontogenic pain 
referred on a blank face (figure 1). Next, they marked the severity of their pain on the Defense and Veterans Pain Rating Scale (DVPRS) ${ }^{42}$ from 0 through 10 (Appendix A). In addition, they
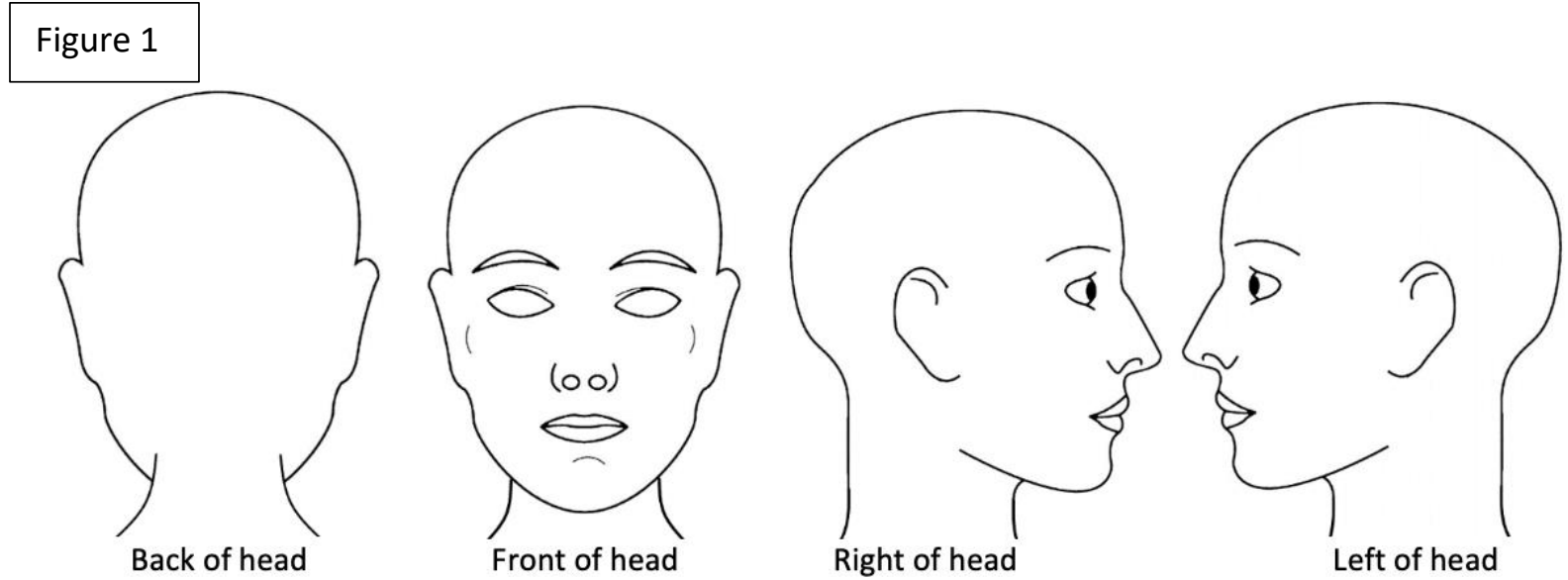

answered supplemental questions in conjunction with the rating scale. At the end of each day, the patient's treatment notes were reviewed and the diagnosis and information on the completed forms were documented. The subject wrote their name on a cover page before completing the rest of the forms. Each cover page and survey contained a four-digit identification number that linked the subject to the survey. After the survey was completed, the cover page was separated from the rest of the survey, given to a third party and placed in a locked location. After the study was completed, the forms were shredded to ensure patient confidentiality.

The following inclusion criteria were utilized to determine which patients participated in the study:

1. Reported pain in the head and neck region

2. Pain of odontogenic origin

3. Consent form signed acknowledging participation or involvement in the study

4. At least 18 years of age

After the data were collected, a statistical analysis was conducted using SPSS statistical analysis software. A chi-square test and binary logistic regression were utilized to examine the 
association between the presence of referred pain (yes or no) with age, gender, race/ethnicity, pulpal diagnosis and the effect of their pain on usual activity, sleep, mood, and stress.

Independent t-tests and ANOVA were utilized to examine the relationship between males and females, and subjects with and without referred pain in regards to how their pain affected their activity, sleep, mood and stress. Finally, the association between referred pain and each sextant of the mouth was examined. 


\section{Chapter 3.}

\section{Results}

Two hundred and fifty subjects were surveyed, and the data was collected and analyzed. Certain groups had to be omitted within the statistical analyses or combined in aggregate into a category of "other" due to their small sample size. In total, 114 of the 250 subjects (45.6\%) were experiencing referred pain at the time they were surveyed.

Among the subjects, 117 were male, 127 were female, and 6 responded as other. Subjects between the ages of 18-28 totaled 71 (28.4\%), ages 29-41 totaled 92 (36.8\%), and ages $42-82$ totaled $87(34.8 \%)$. The average age of the entire subject pool was 38.7 years old. The age ranges were chosen by evenly splitting up the patient pool after the first 100 subjects were surveyed. Age failed to reach significance with the presence or absence of referred pain (demographic details in Tables I-III and Figures 2-4). However, females (70 subjects and $61.4 \%$ of those with referred pain) tended to experience more referred pain than males (42 subjects and $36.8 \%$ of those with referred pain). An adjusted odds ratio for gender, with the "other" group not included due to its small sample size, was calculated and found to be 2.19 (95\% CI 1.31, 3.67; $\mathrm{p}<0.01$ ). This indicates that there is a statistically significant association with the female gender and the presence of referred odontogenic pain. Additionally, the younger age group (ages 18-28) experienced referred pain slightly more often than the other two age groups (ages 29-41 and 4282) per Figure 3. 


\begin{tabular}{|l|r|r|}
\hline Table I. Gender & Frequency & Percent \\
\hline Male & 117 & 46.8 \\
\hline Female & 127 & 50.8 \\
\hline Other & 6 & 2.4 \\
\hline Total & 250 & 100 \\
\hline
\end{tabular}

Table I. Frequency and percentages of subjects' gender.

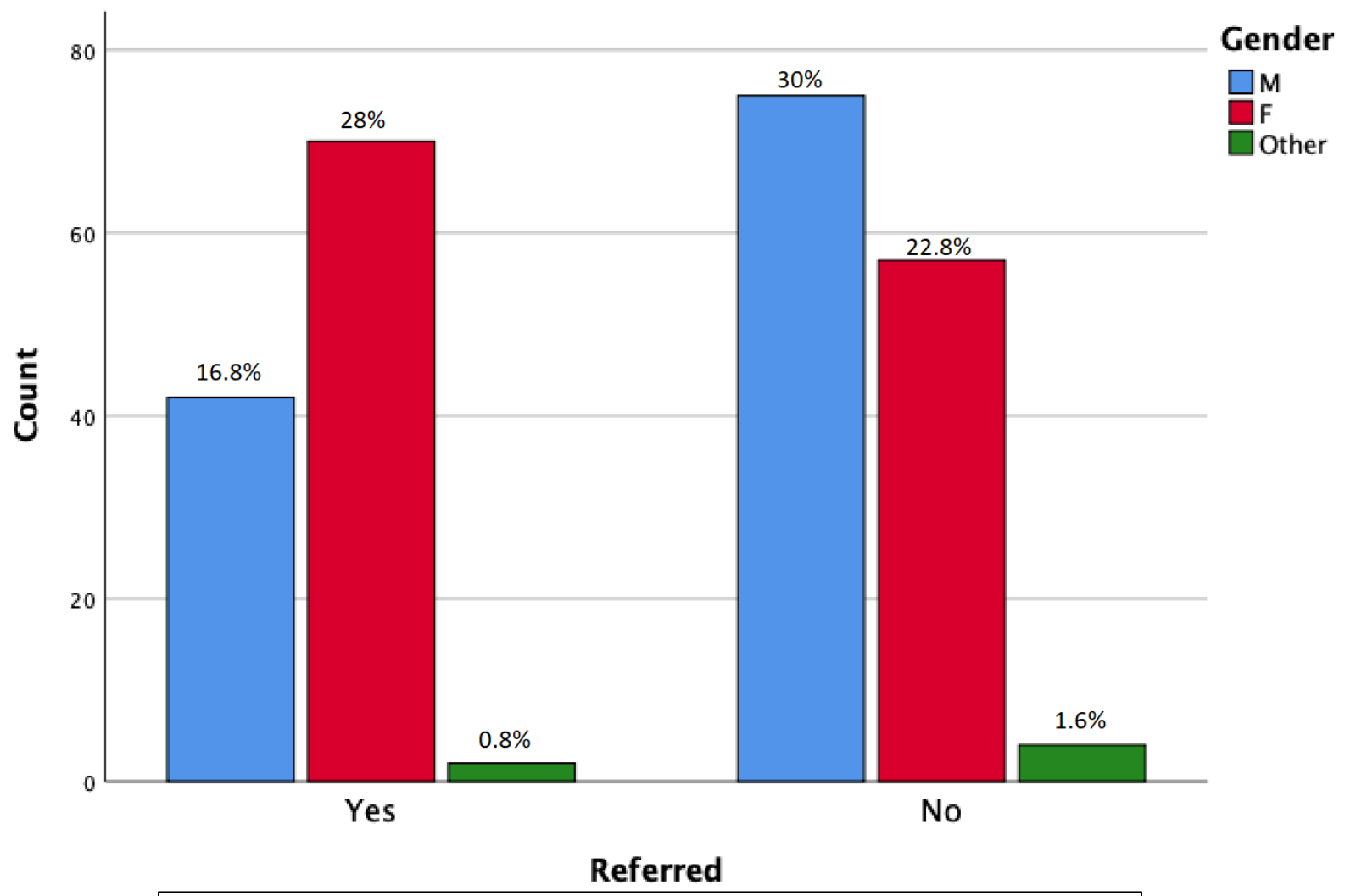

Figure 2. Referred pain vs. gender, $n=250$ *Statistically significant 


\begin{tabular}{|l|r|r|}
\hline Table II. Age Ranges & Frequency & Percent \\
\hline $18-28$ & 71 & 28.4 \\
\hline $29-41$ & 92 & 36.8 \\
\hline $42-82$ & 87 & 34.8 \\
\hline Total & 250 & 100 \\
\hline
\end{tabular}

Table II. Frequency and percentages of subjects' age.

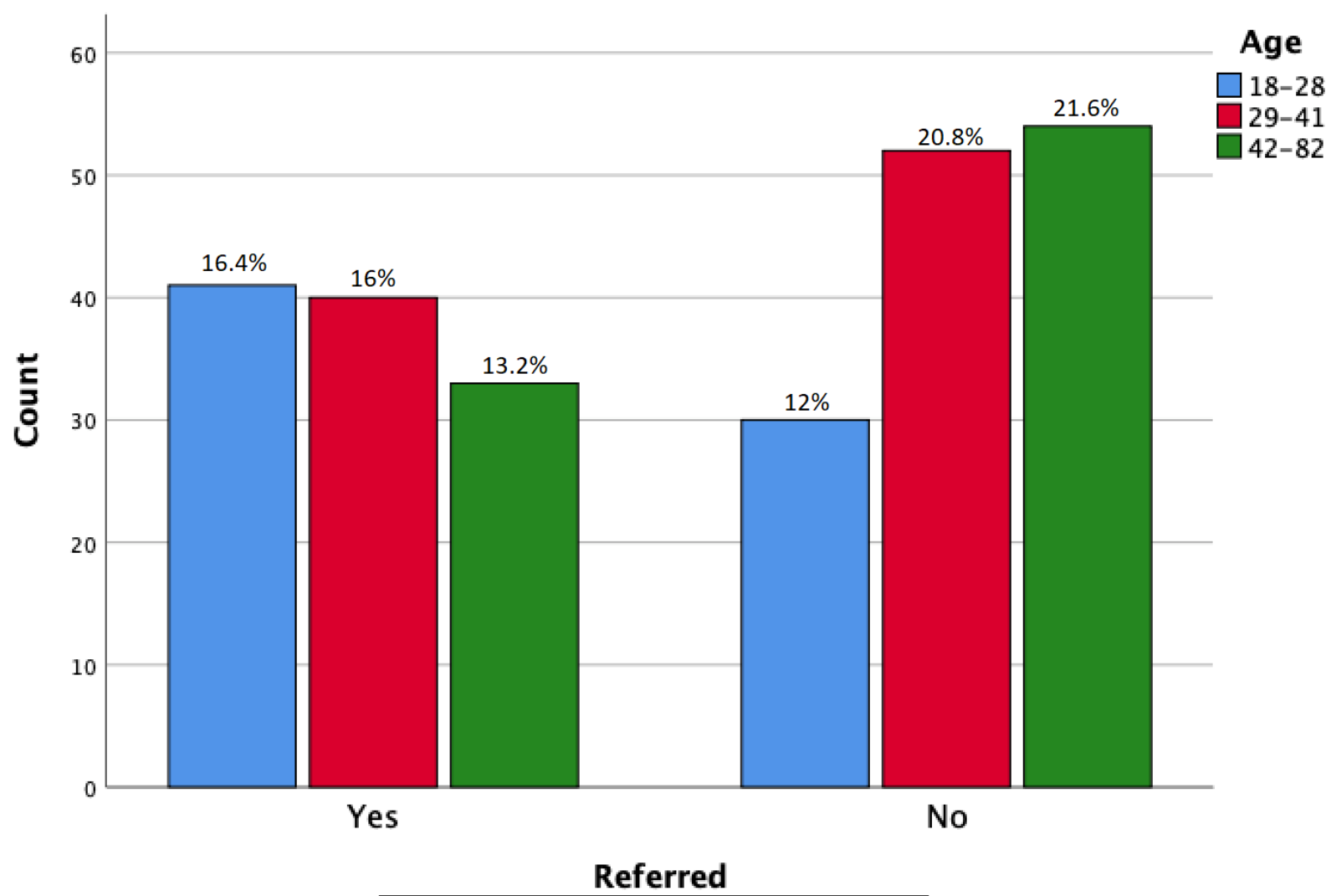

Figure 3. Referred pain vs. age, $n=250$ 


\begin{tabular}{|l|r|r|}
\hline Table III. Race/Ethnicity & Frequency & Percent \\
\hline White & 221 & $88.4 \%$ \\
\hline African American & 15 & $6.0 \%$ \\
\hline Other & 14 & $5.6 \%$ \\
\hline Total & 250 & $100 \%$ \\
\hline
\end{tabular}

Table III. Frequency and percentages of subjects' race/ethnicity.

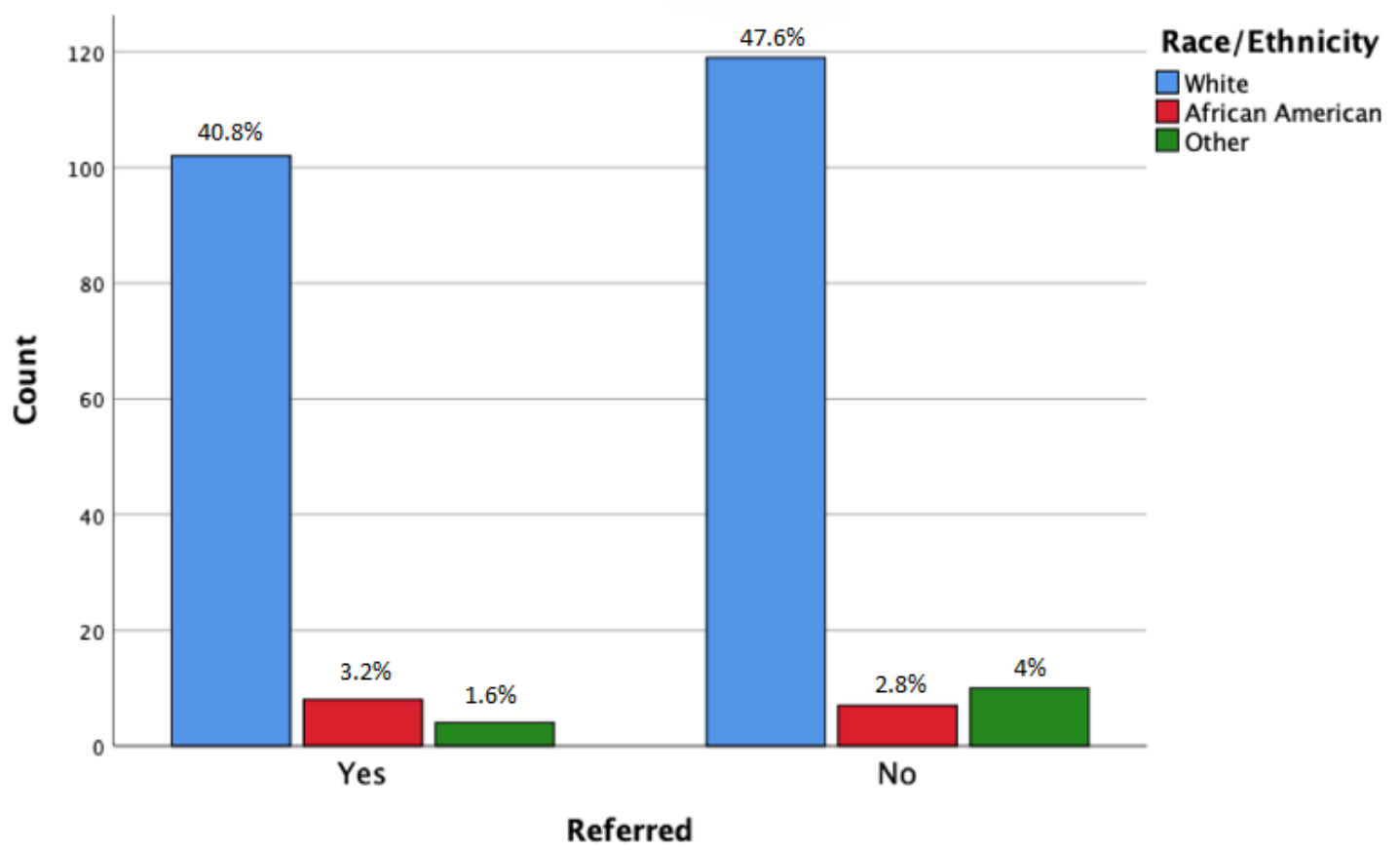

Figure 4. Referred pain vs. race/ethnicity, $n=250$ 


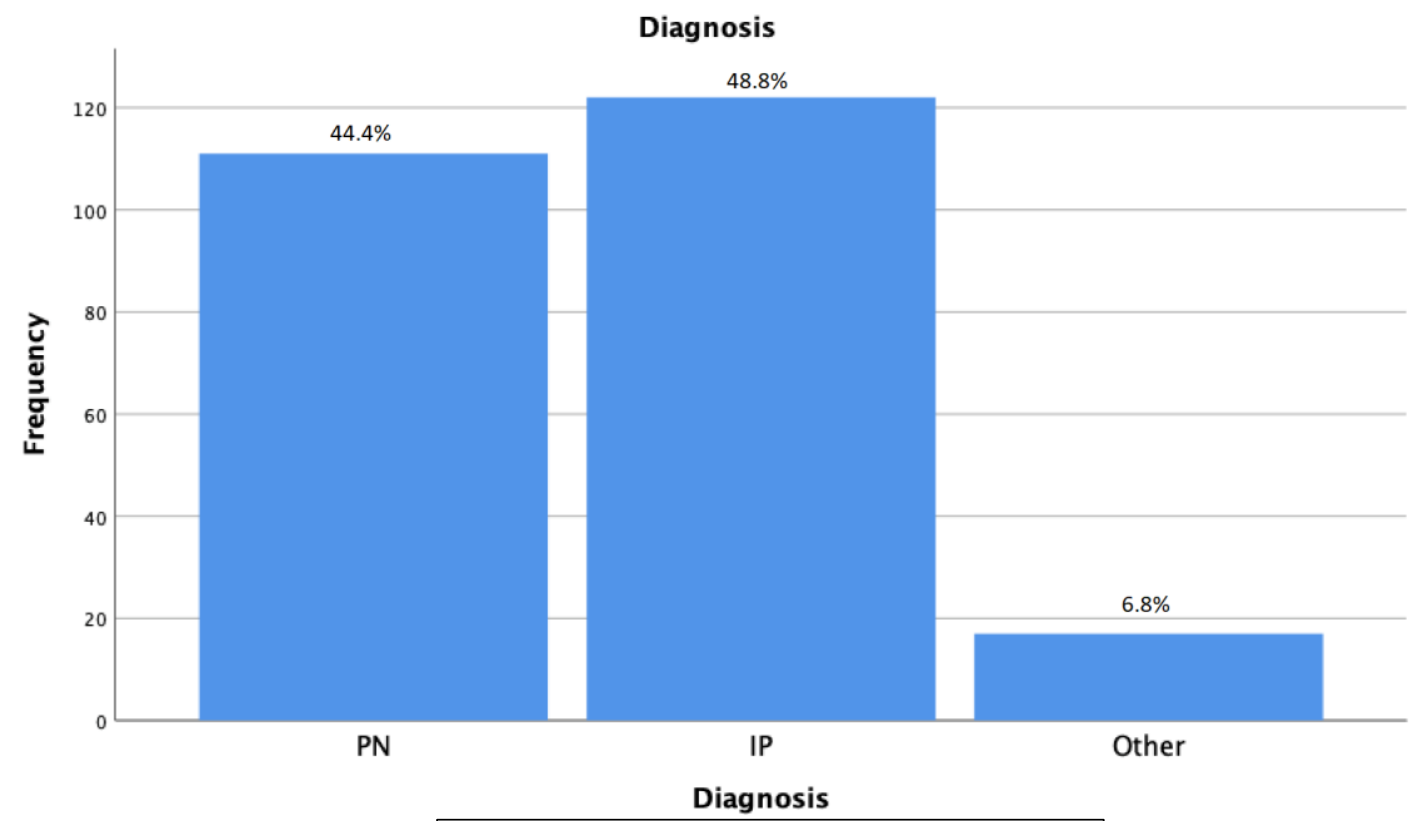

Figure 5. Diagnosis frequencies, $n=250$

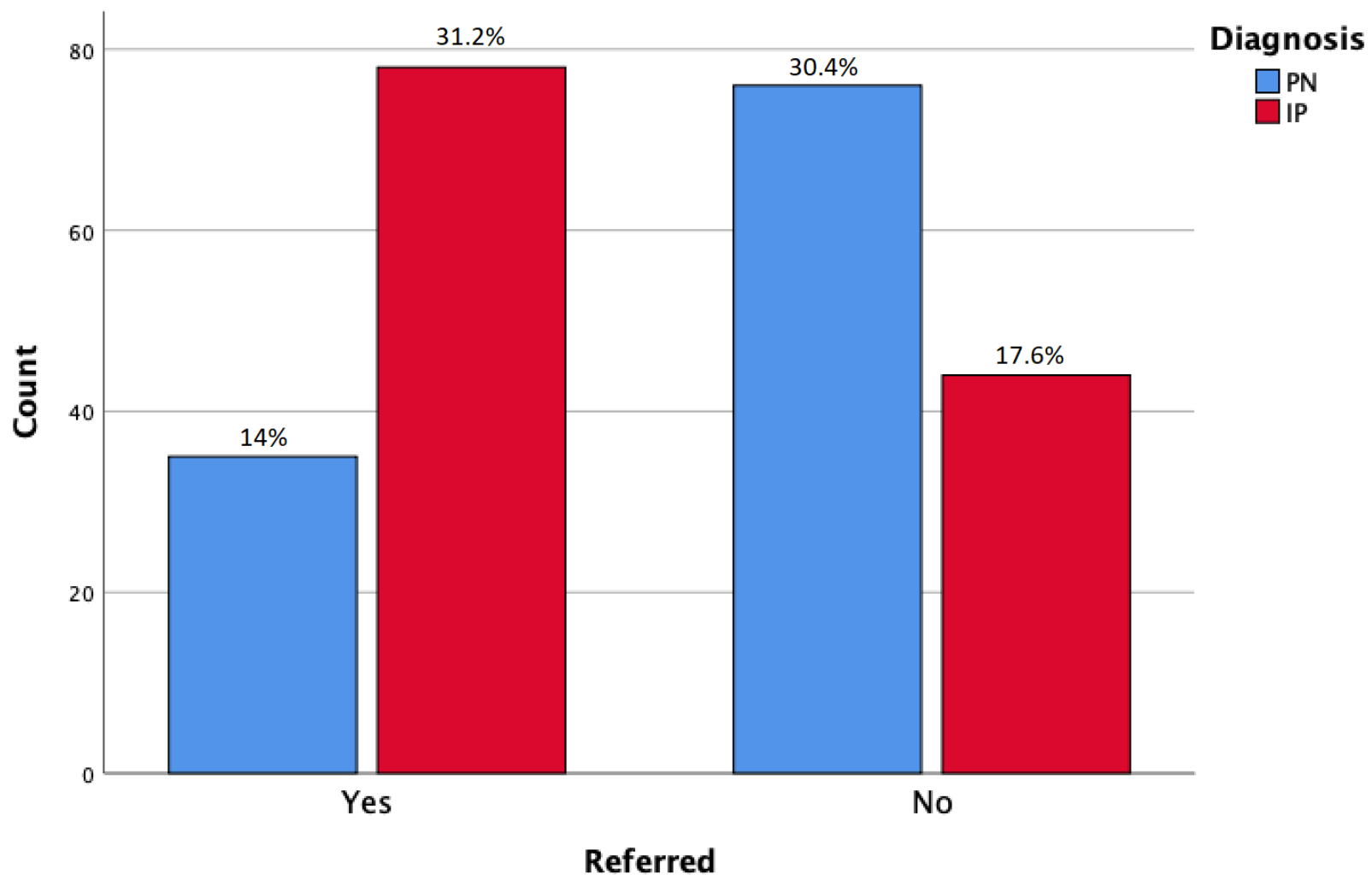

Figure 6: PN and IP vs. Referred Pain (PN: Pulp Necrosis, IP: Irreversible Pulpitis), percentages are of the entire subject pool, other diagnoses are excluded due to small sample size, $n=233$ *Statistically significant 
Additionally, of the 250, 122 (48.8\%) subjects' teeth had a pulpal diagnosis of irreversible pulpitis (IP) and 111 (44.4\%) had a pulpal diagnosis of pulp necrosis (PN). The remainder had a pulpal diagnosis of reversible pulpitis, previously initiated therapy or previously treated. Of the 114 subjects experiencing referred odontogenic pain, 78 (68.4\%) had a pulpal diagnosis of irreversible pulpitis, 35 (30.7\%) had a diagnosis of pulp necrosis (figure 6), and one subject had a pulpal diagnosis other than IP and PN. A statistically significant association was made between subjects with a pulpal diagnosis of irreversible pulpitis and the presence of referred pain. The adjusted odds ratio of referred pain for a diagnosis of irreversible pulpitis as compared with pulp necrosis was 3.85 (95\% CI 2.23, 6.64;p<0.01). Table IV outlines the pulpal diagnoses of pulp necrosis and irreversible pulpitis and the amount of instances that each diagnosis was associated with referred pain.

\begin{tabular}{|c|c|c|c|c|c|}
\hline \multirow{2}{*}{ Table IV. } & & \multicolumn{3}{|c|}{ Pulpal Diagnosis } & \multirow[b]{2}{*}{ Total } \\
\hline & & PN & IP & Other & \\
\hline \multirow{3}{*}{ 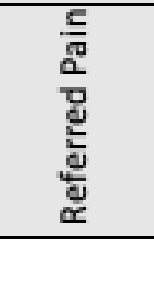 } & Yes & 35 & 78 & 1 & 114 \\
\hline & No & 76 & 44 & 16 & 136 \\
\hline & Total & 111 & 122 & 17 & $n=250$ \\
\hline
\end{tabular}

Table IV. Incidence of Referred Pain for pulp necrosis (PN), irreversible pulpitis (IP) and the other pulpal diagnoses

The DVPRS 1-10 scale within the survey assessed how the subjects' pain affected their activity, sleep, mood, and stress in the past 24 hours. Mean values were established among the subjects and were outlined in Table V and VI. The scores were similar between irreversible pulpitis and pulpal necrosis, but they were higher than the other pulpal diagnosis groups. Additionally, subjects with referred odontogenic pain experienced statistically significantly larger effects to their activity $(\mathrm{t}(235)=4.371, \mathrm{p}<0.01)$, sleep $(\mathrm{t}(234)=4.709, \mathrm{p}<0.01), \operatorname{mood}$ 
$(\mathrm{t}(235)=4.304, \mathrm{p}<0.01)$, and stress $(\mathrm{t}(235)=4.582, \mathrm{p}, 0.01)$ as compared to subjects without referred odontogenic pain (values outlined in Table V and Figures 7-14).

\begin{tabular}{|l|l|l|l|l|l|}
\hline \multirow{2}{*}{ Table V. } & \multicolumn{5}{|c|}{ Mean Values on DVPRS scale (standard deviation in parentheses) } \\
\cline { 2 - 6 } & Irreversible Pulpitis & Pulp Necrosis & \multicolumn{1}{|c|}{ Other } & w/ Referred Pain & w/o Referred Pain \\
\hline Activity & $6.66(2.36)$ & $6.68(2.65)$ & $4.18(1.78)$ & $7.23(2.19)$ & $5.84(2.64)$ \\
\hline Sleep & $6.36(3.07)$ & $6.36(3.04)$ & $3.31(2.82)$ & $7.13(2.68)$ & $5.29(3.24)$ \\
\hline Mood & $6.42(2.69)$ & $6.62(2.87)$ & $3.71(2.78)$ & $7.14(2.59)$ & $5.59(2.90)$ \\
\hline Stress & $6.38(2.70)$ & $6.47(2.77)$ & $3.71(2.59)$ & $7.08(2.48)$ & $5.48(2.87)$ \\
\hline
\end{tabular}

Table V. Mean Values (with Standard Deviation) on the DVPRS scale for how the subject's odontogenic pain has affected their Activity, Sleep, Mood, and Stress in the last 24 hours for different diagnosis and the presence or absence of referred pain

Males and females were compared and the DVPRS means were examined in each category for each gender (table VI). Pain within females resulted in a larger effect on their activity $(\mathrm{t}(229)=-2.757, \mathrm{p}<0.01), \operatorname{mood}(\mathrm{t}(229)=-3.206, \mathrm{p}<0.01)$, and stress $(\mathrm{t}(229)=-2.941$, $\mathrm{p}<0.01$ ), all of which were statistically significant. Females also exhibited a numerically larger effect on their sleep, compared to males, but no reliable difference between the subjects was found $(\mathrm{t}(228)=-1.881, \mathrm{p}=0.061)$.

\begin{tabular}{|l|c|c|}
\hline Table VI. & Mean Values on DVPRS scale (standard deviation in parentheses) \\
\hline & Males, $\mathrm{n}=117$ & Females, $\mathrm{n}=127$ \\
\hline Activity & $6.04(2.58)$ & $6.94(2.39)$ \\
\hline Sleep & $5.78(3.10)$ & $6.55(3.06)$ \\
\hline Mood & $5.71(2.73)$ & $6.88(2.81)$ \\
\hline Stress & $5.70(2.64)$ & $6.75(2.77)$ \\
\hline
\end{tabular}

Table VI. Mean Values (with Standard Deviation) on the DVPRS scale for how the subject's odontogenic pain has affected their Activity, Sleep, Mood, and Stress in the last 24 hours with the male and female gender groups

Two-way analyses of variants were conducted on gender by the presence or absence of referred pain and revealed no significant interactions. 


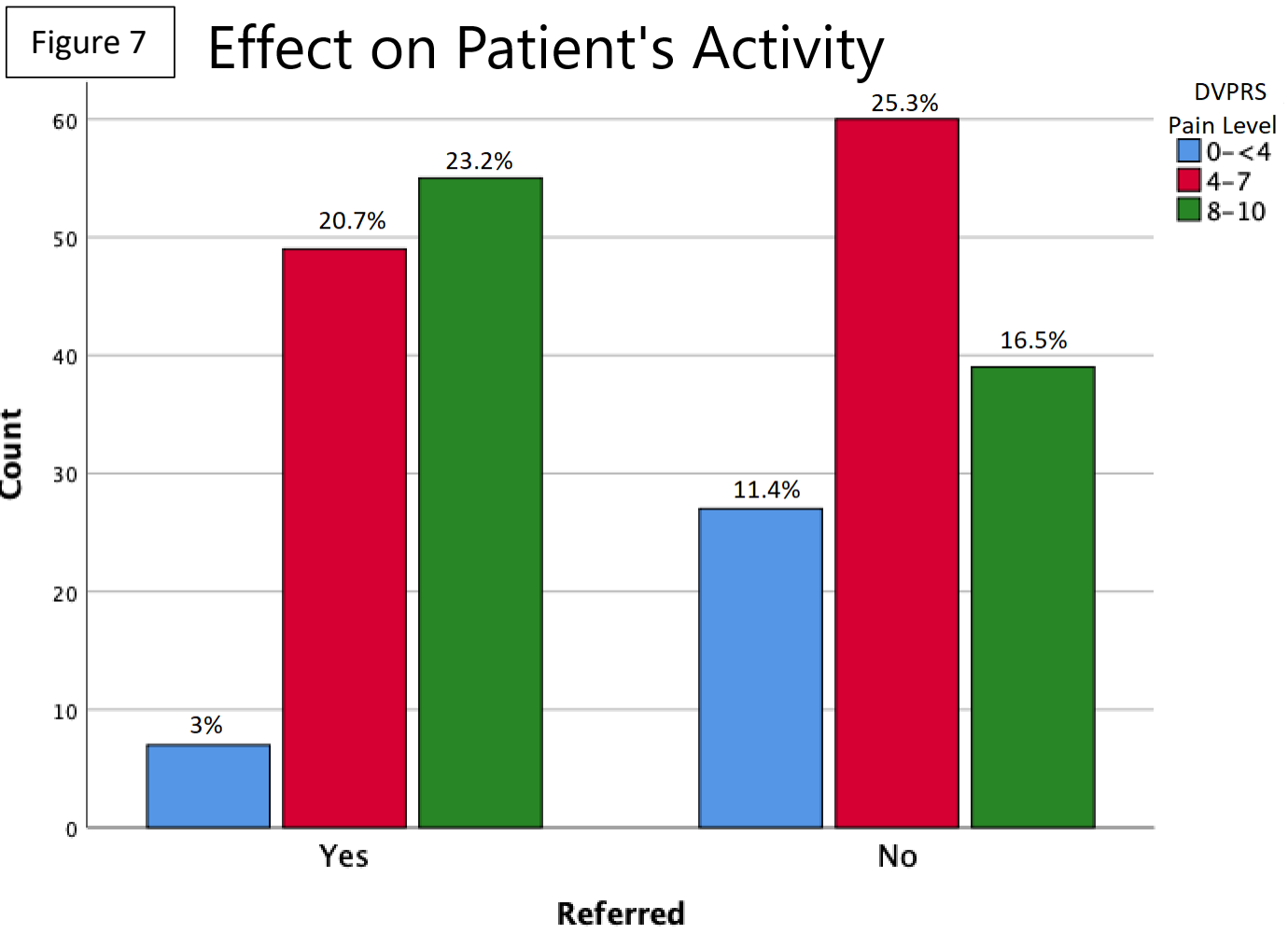

Figure 8 Effect on Patient's Mood

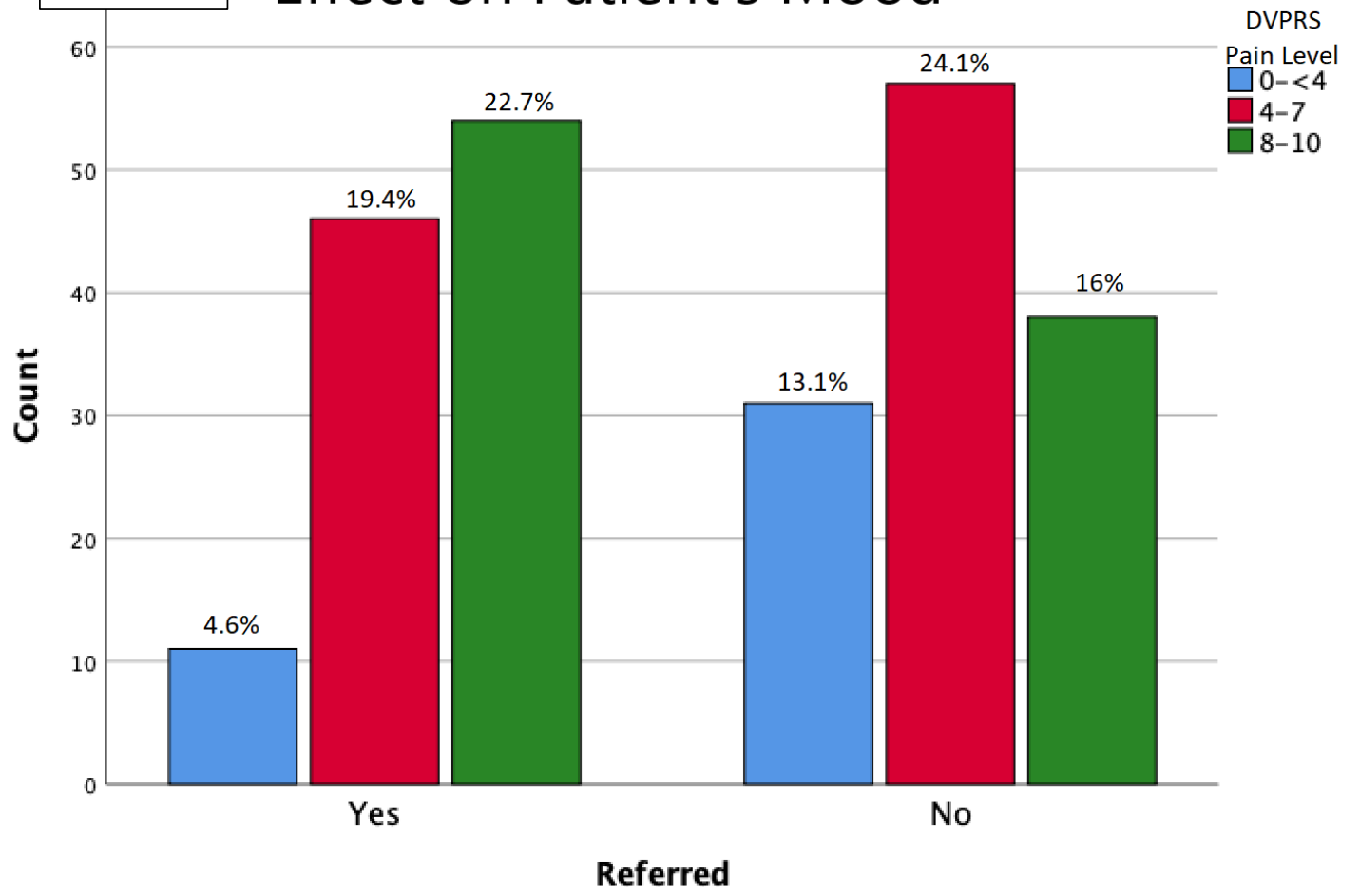



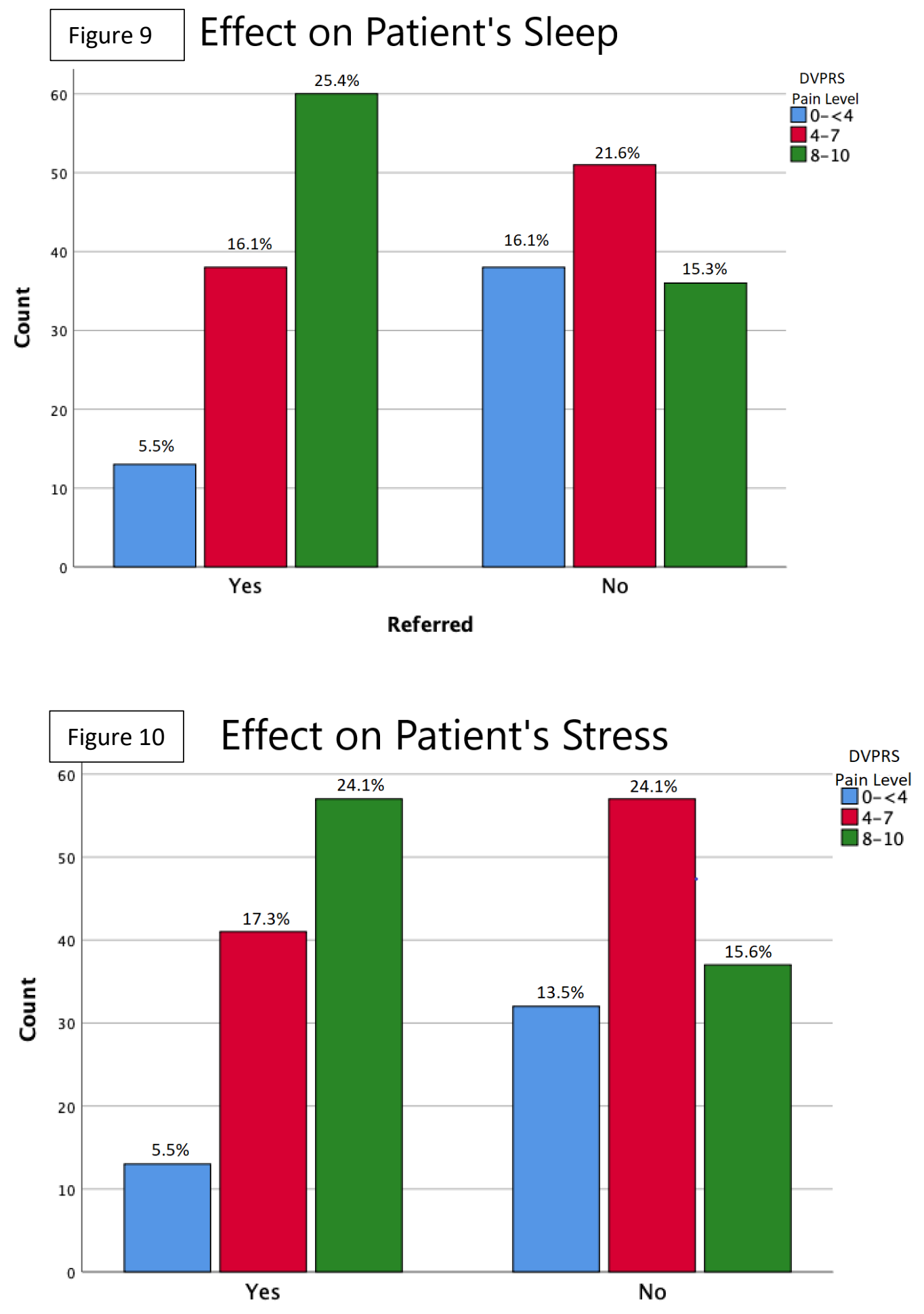

Referred

Figures 7-10. The presence or absence of referred odontogenic pain vs. how the subjects' pain affected their Activity, n=237 (Figure 7), Mood, n=237 (Figure 8), Sleep, n=236 (Figure 9), and Stress, n=237 (Figure 10), not all subjects chose to fill out this portion of the survey 


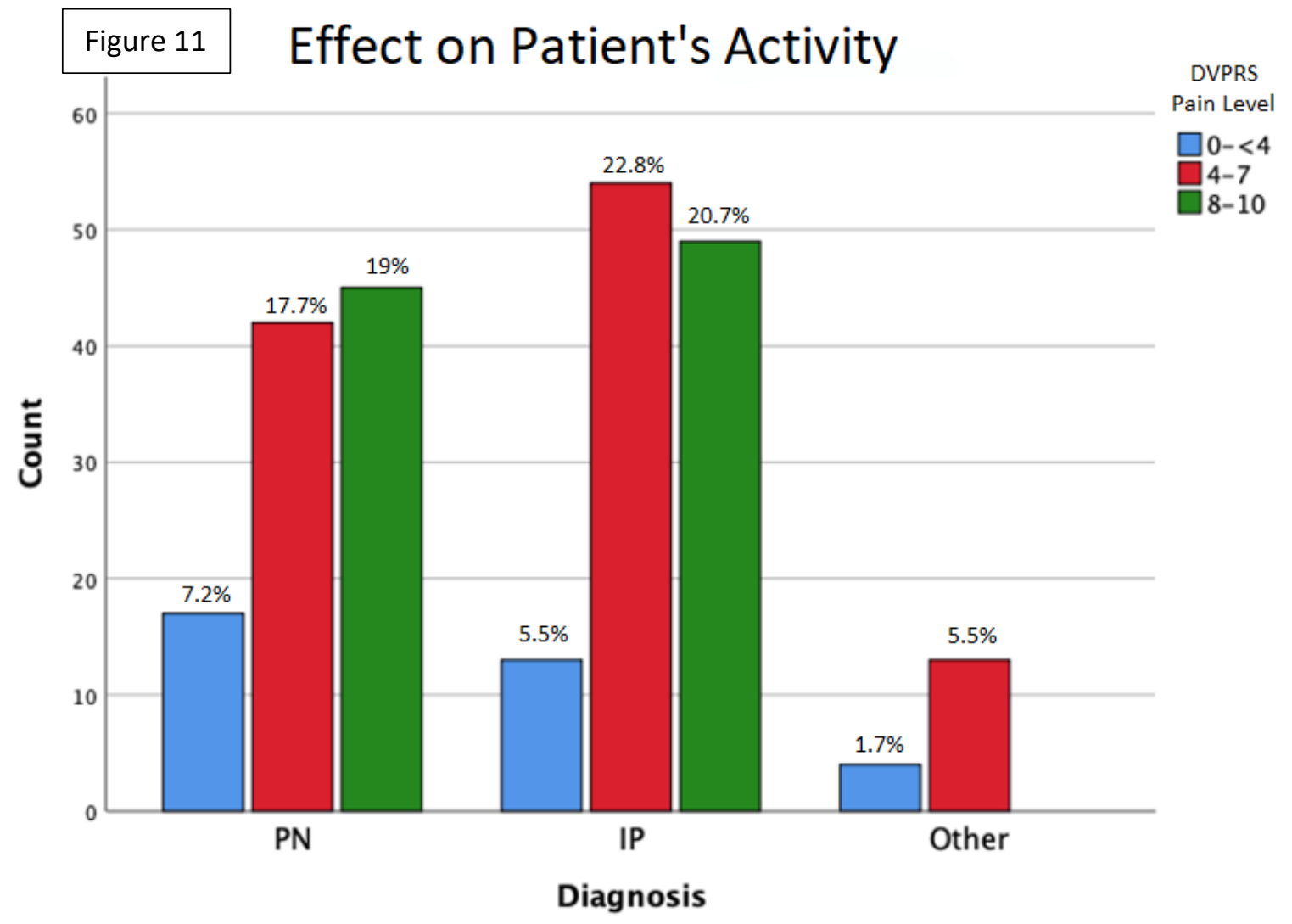

Figure 12

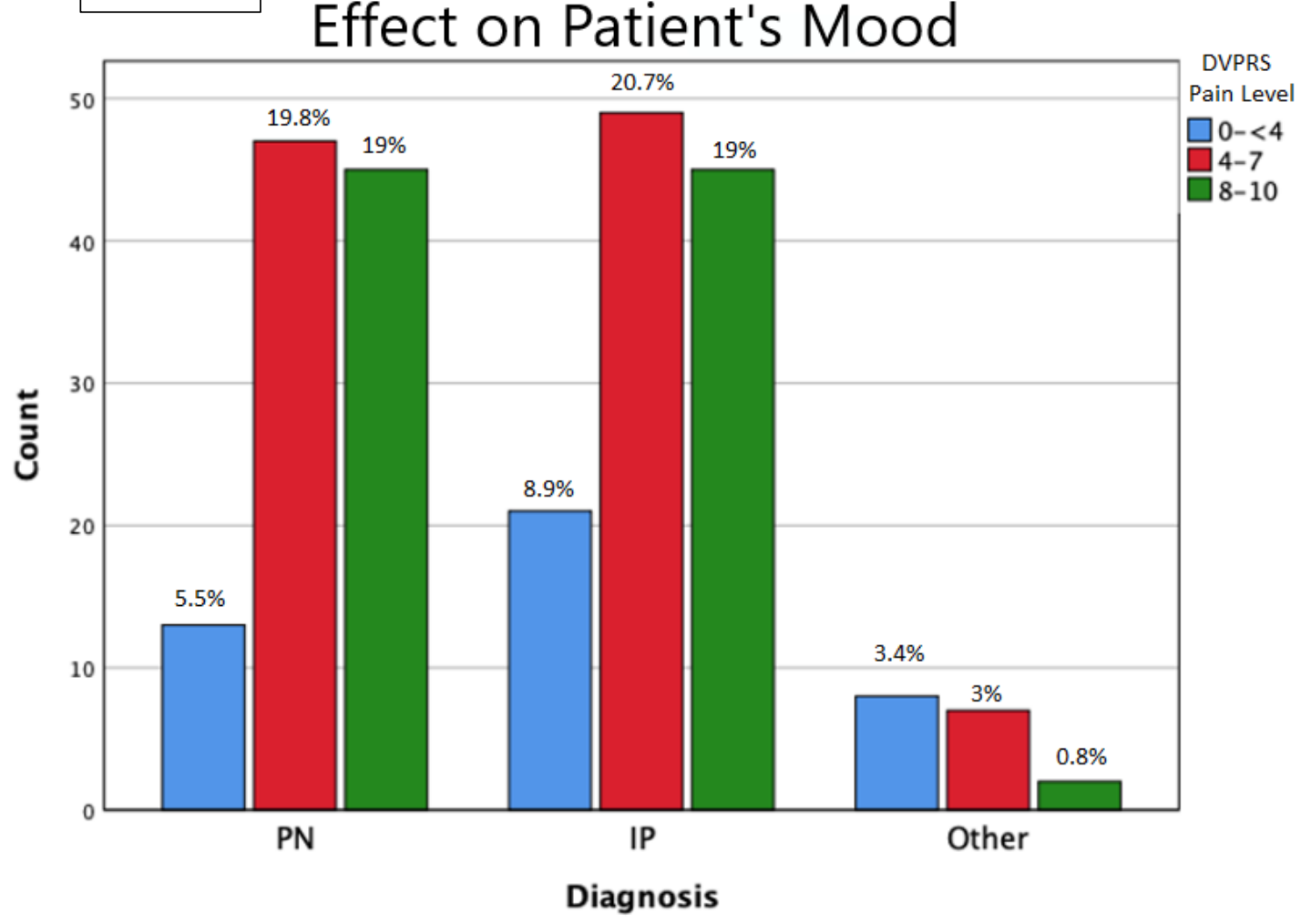



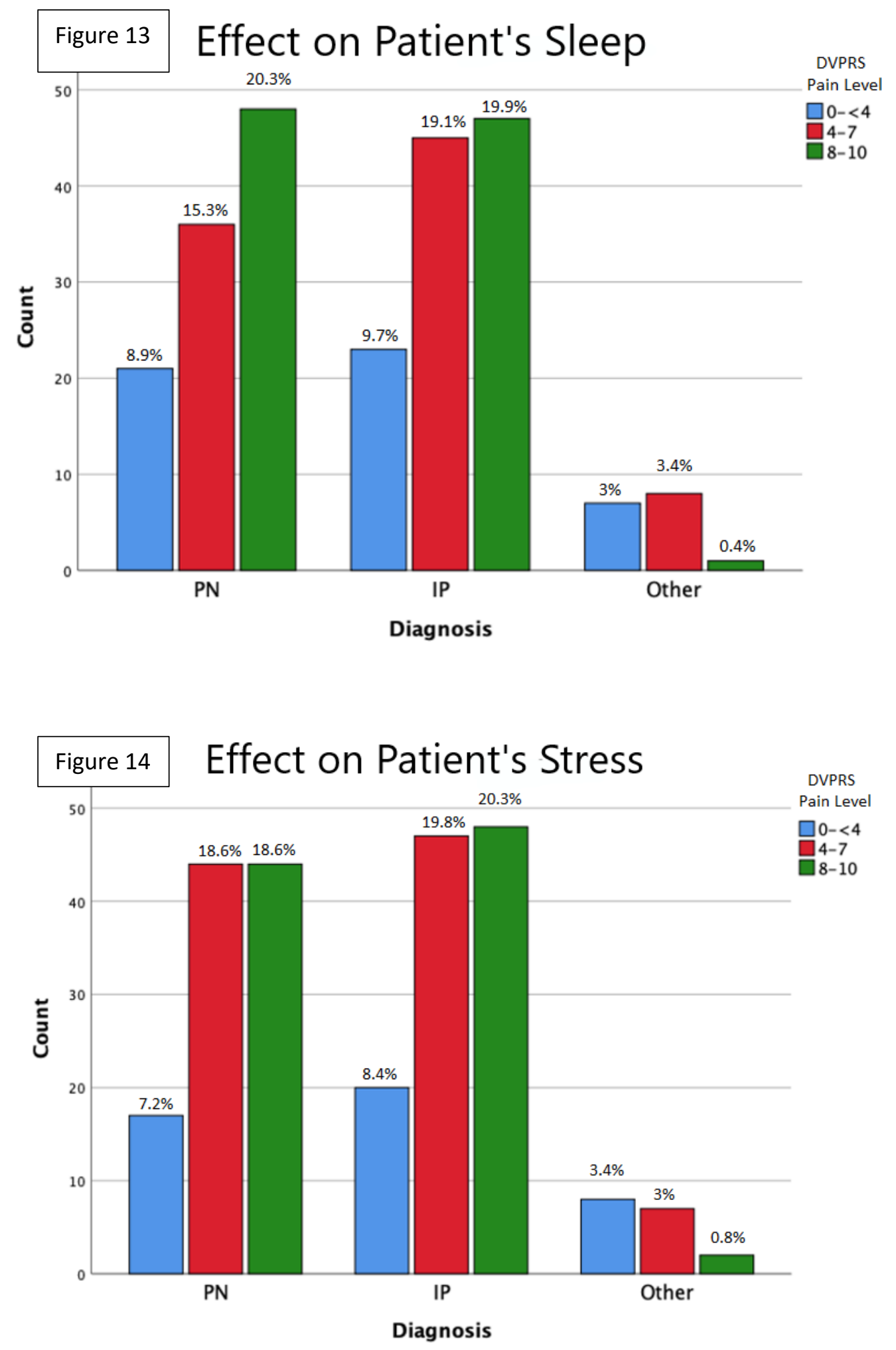

Figures 11-14. Pulpal diagnosis vs. how the subjects' pain affected their Activity, $n=237$ (Figure 11), Mood, n=237 (Figure 12), Sleep, n=236 (Figure 13), and Stress, n=237 (Figure 14), not all subjects chose to fill out this portion of the survey 
During the analyzation process, the dentition was separated into 6 sextants: maxillary molars, maxillary premolars, maxillary anteriors, mandibular molars, mandibular premolars, and mandibular anteriors. The frequency that each sextant caused referred pain is outlined in Figure 15 and a referred pain heat map was created for each sextant (Figures 16-21). The heat maps are color coded and the colors are assigned according to the frequency of referral to each location: red (highest frequency) $>$ orange $>$ yellow $>$ green (lowest frequency). No teeth were found to refer pain to the contralateral side of the face.

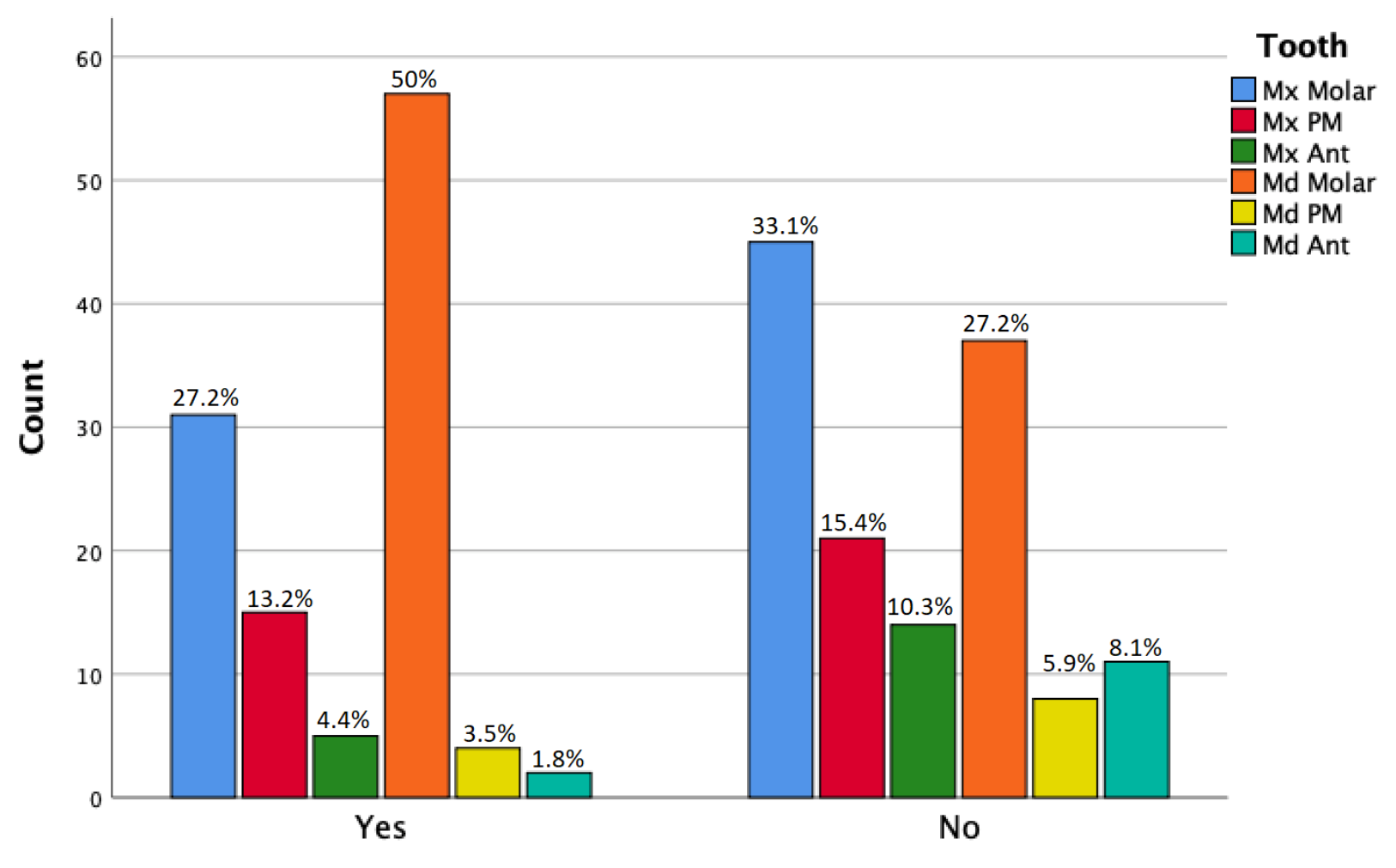

\section{Referred}

Figure 15. Referred pain vs. each sextant of teeth that are the source of the pain (Mx Molar: 1-3, 14-16, Mx PM: 4-5, 12-13, Mx Ant: 6-11, Md Molar: 17-19, 30-32, Md PM: 20-21, 28-29, Md Ant: 22-27), percentages of each tooth are within each referred pain group (yes: $n=114, n o: n=136$ ) 


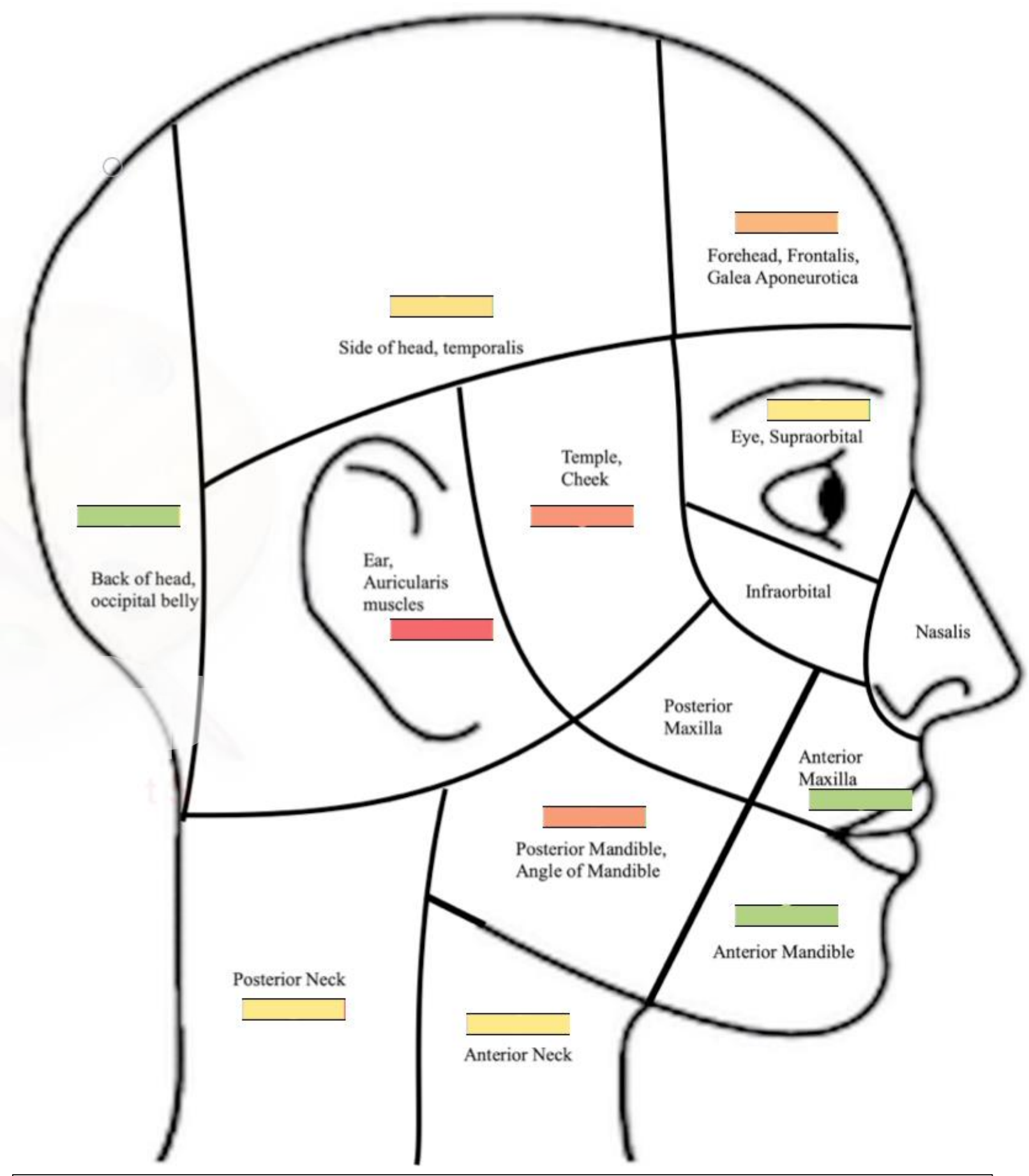

Figure 16. Heat map associated with maxillary molars, $n=31$, red $>$ orange $>$ yellow $>$ green 


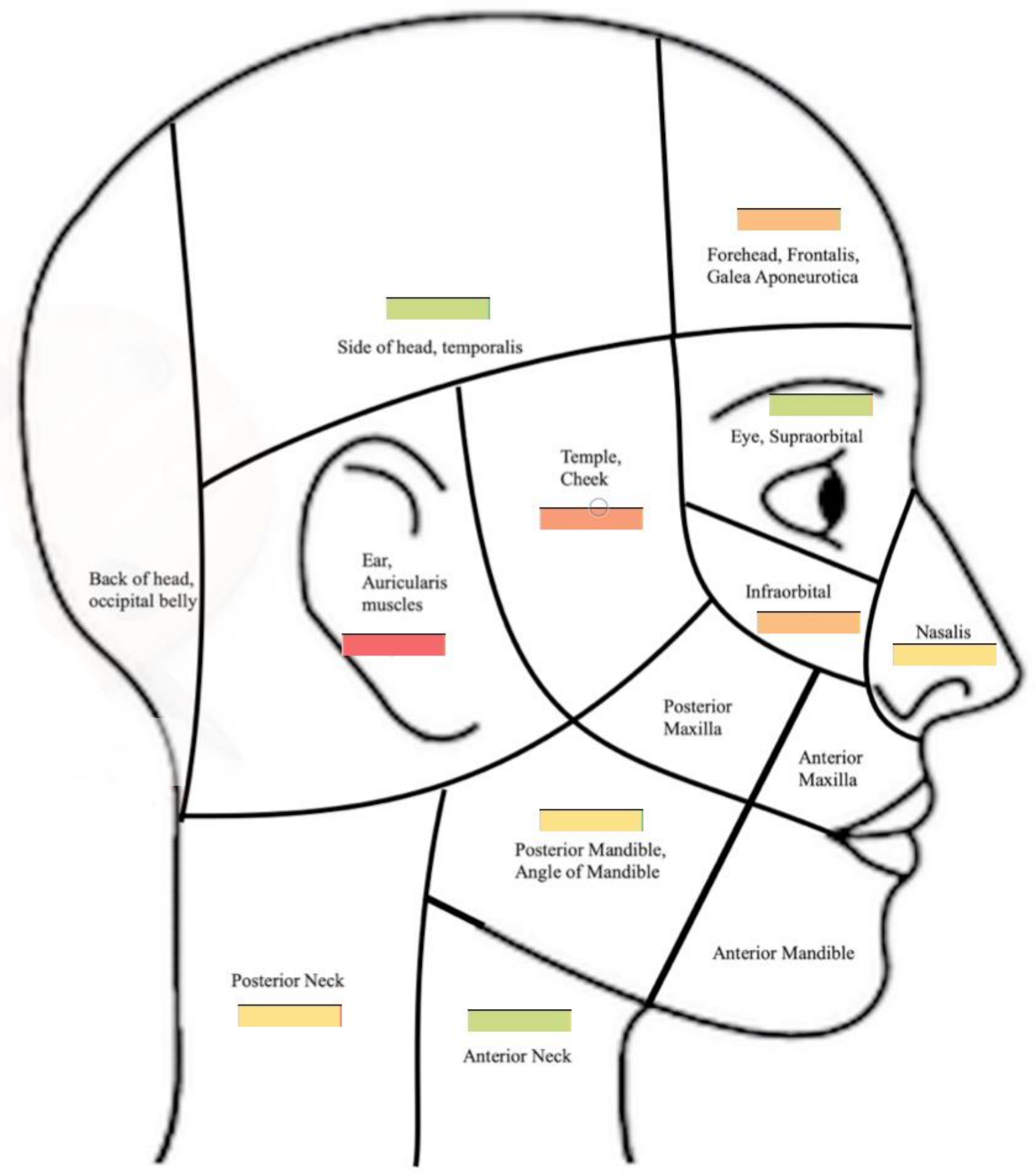

Figure 17. Heat map associated with maxillary premolars, $n=15$, red $>$ orange $>$ yellow $>$ green 


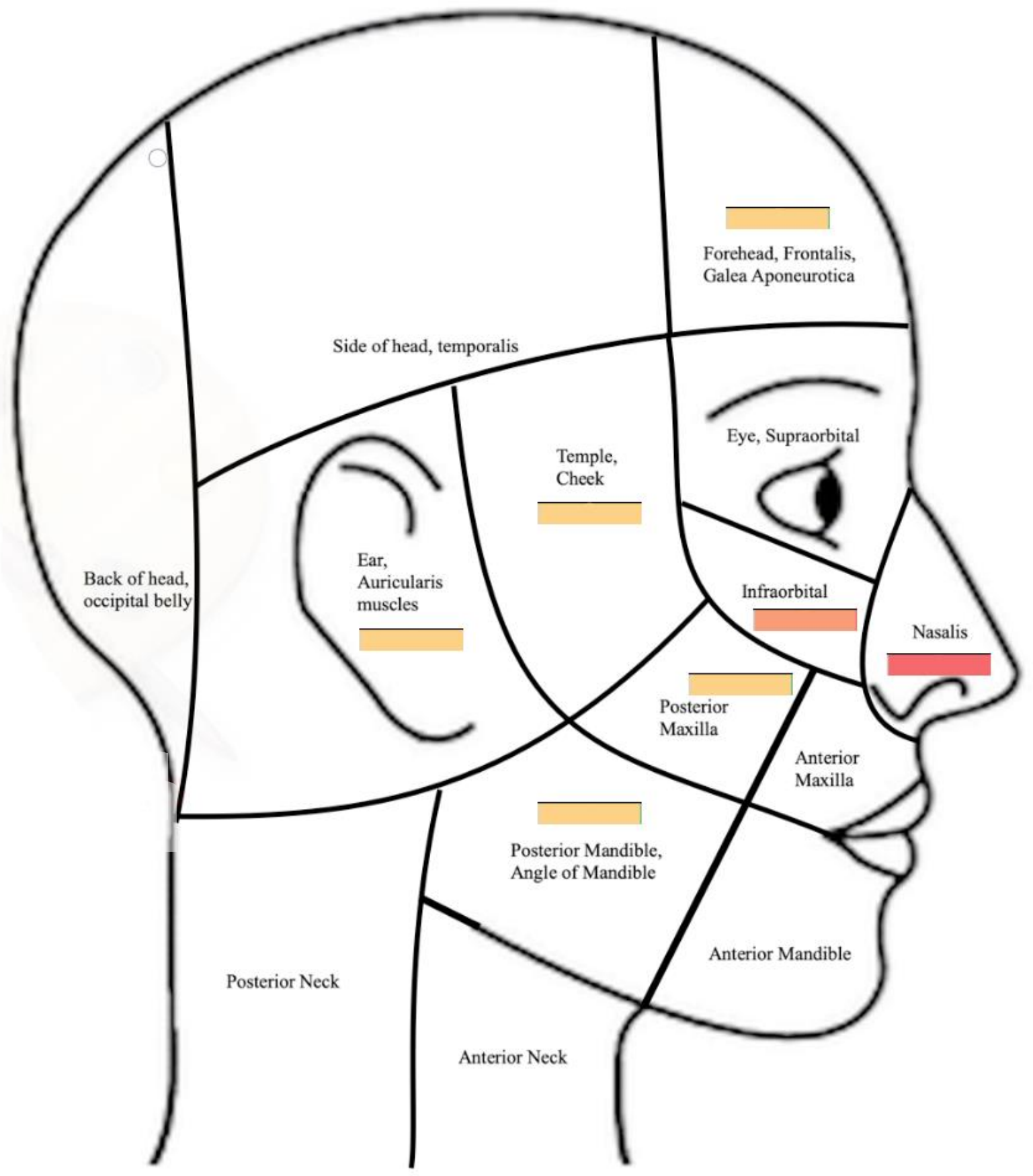

Figure 18. Heat map associated with maxillary anterior teeth, $n=5$, red $>$ orange $>$ yellow 


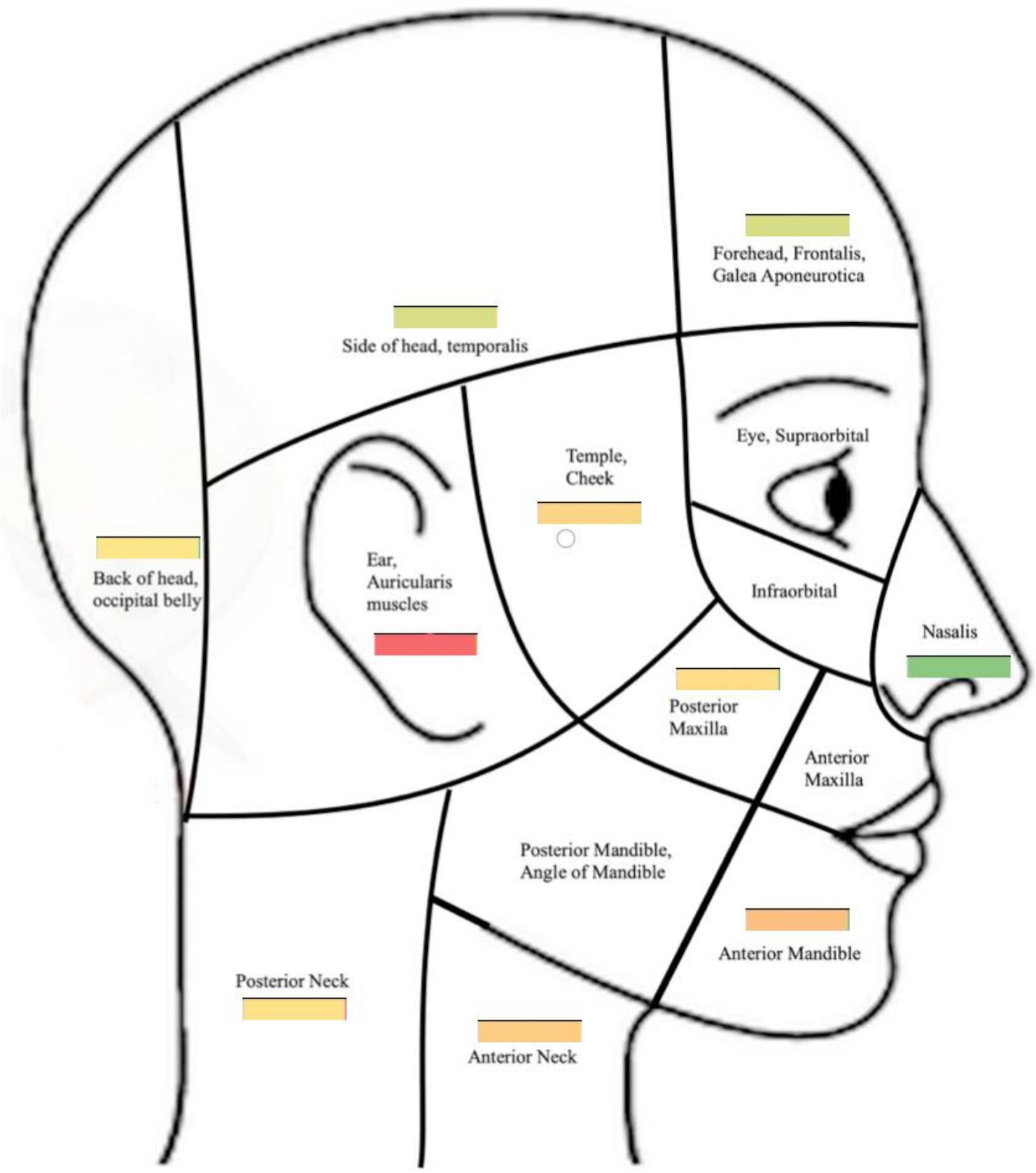

Figure 19. Heat map associated with mandibular molars, $n=57$, red $>$ orange $>$ yellow $>$ green 


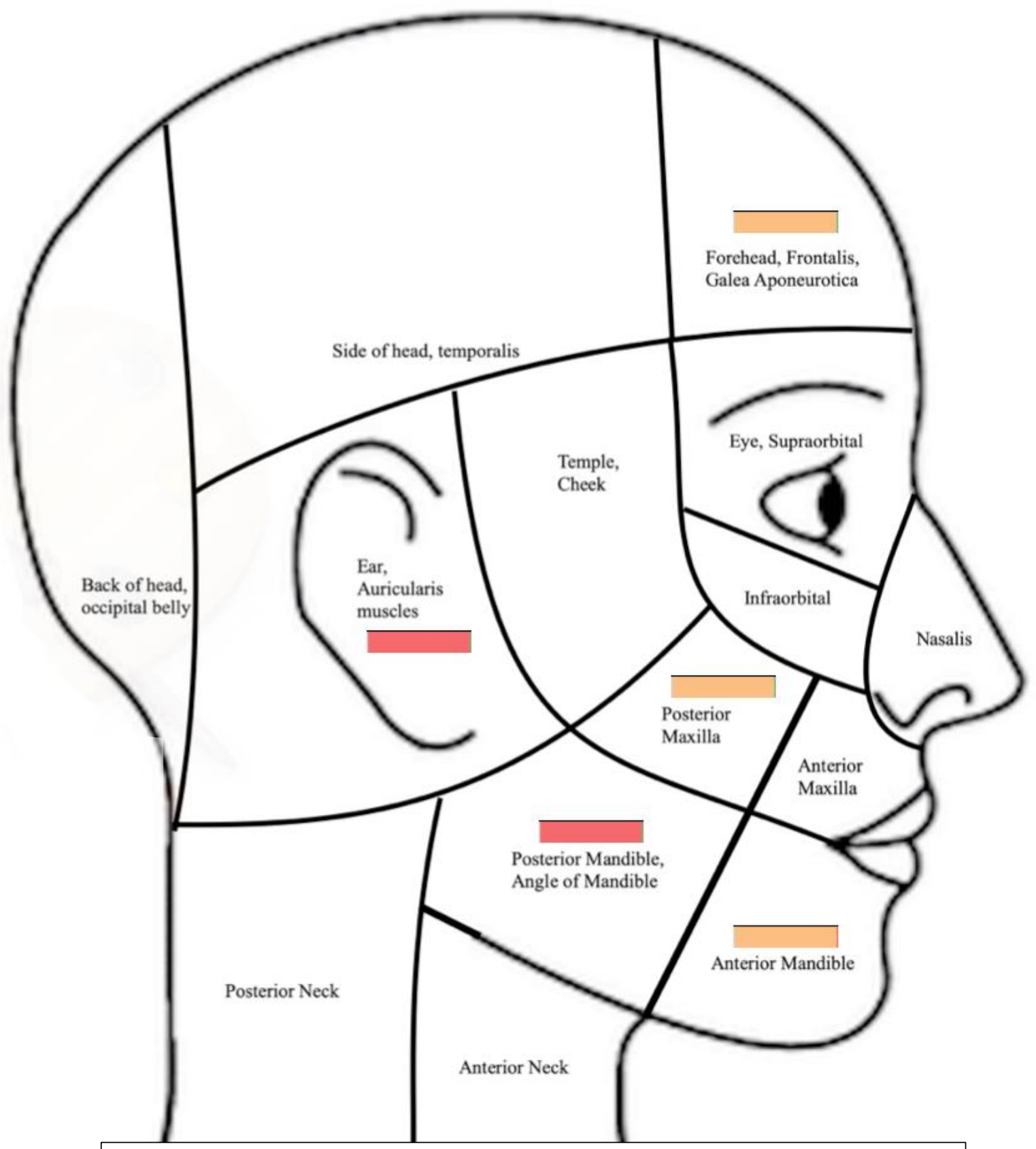

Figure 20. Heat map associated with mandibular premolars, $n=4$, red $>$ orange 


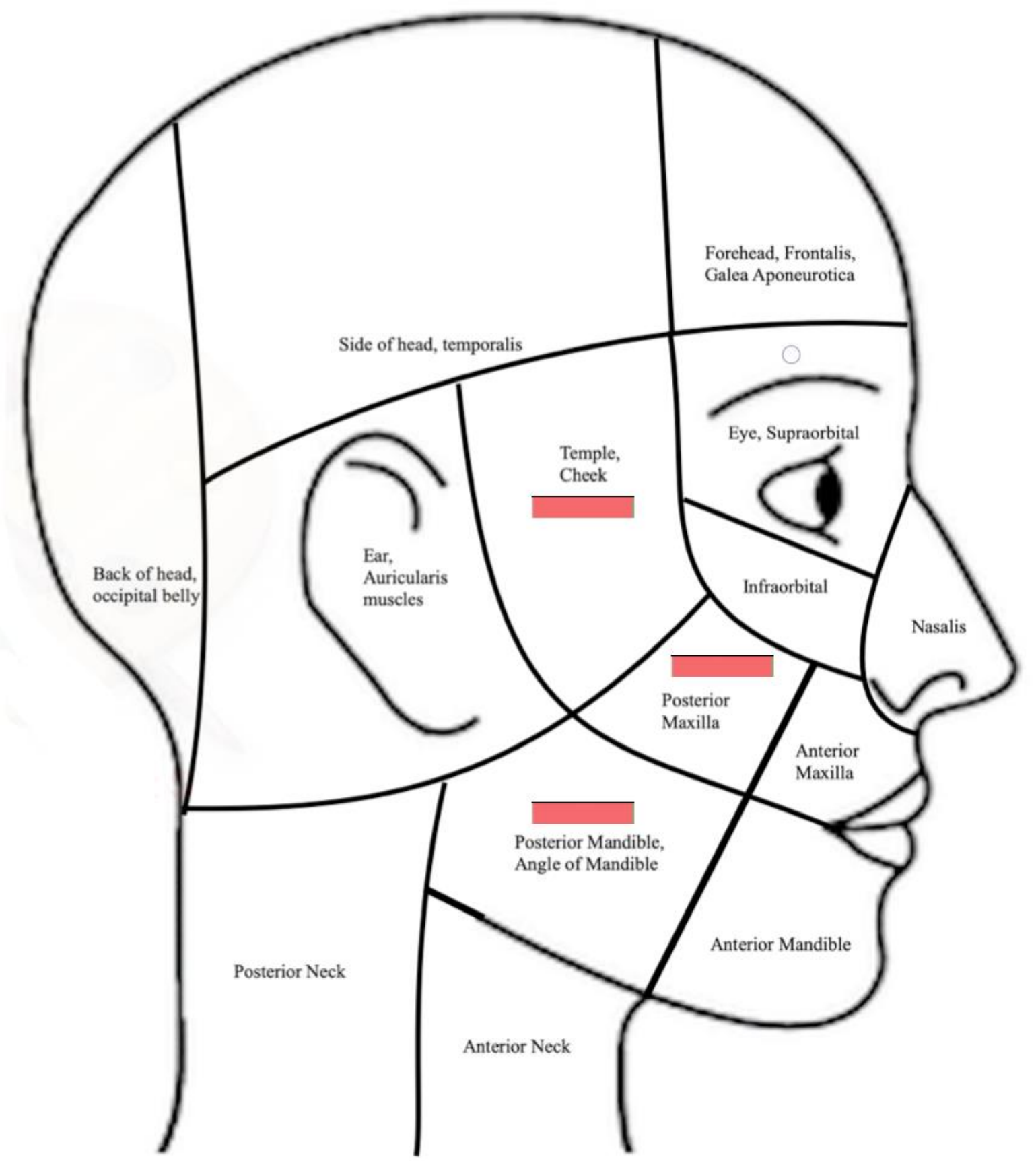

Figure 21. Heat map associated with mandibular anterior teeth, $n=2$, one member of the subject pool experienced referred pain to these areas 


\section{Chapter 4.}

\section{Discussion}

Referred odontogenic pain was found to be associated with the pulpal diagnosis of irreversible pulpitis. This substantiates the theory that vital pulps are primarily responsible for the presence of referred pain. The observation, moreover, that some nonvital pulps were also associated with referred pain suggests that necrotic pulps can also be responsible for referred pain, or it could mean that the $31.5 \%$ of pulps with a diagnosis of pulp necrosis that caused referred pain, in fact, had partial pulpal vitality. The only way to be absolutely sure of this point would be to extract, section, and histologically evaluate the pulp of a tooth that is causing referred pain. This could be a subject of future research.

Jespersen et al. ${ }^{43}$ found that the lack of response to cold testing had a 0.86 positive predictive value, meaning that $86 \%$ of negative cold tests correspond to true pulpal necrosis. The instances where a negative cold test does not accurately diagnose the pulp as necrotic (approximately $14 \%{ }^{43}$ ) could also be responsible for the subjects diagnosed with pulp necrosis and were experiencing referred pain.

Another explanation to why pulp necrosis may yield referred pain could be the anatomical proximity of the associated apical periodontitis to nerves such as the inferior alveolar nerve or the mental nerve. The pressure of the apical periodontitis could cause the nerve fibers to activate and send painful stimuli to the trigeminal ganglion and therefore, yield referred pain via convergence. This theory is by no means substantiated from the literature, but it could be the subject of future research. 
Other statistically significant findings from this investigation are the association between the female gender and the presence of referred pain and the effects the pain has on the subject's activity, mood and stress. The connection between females and referred pain has been previously recorded within medical journals, as exemplified by Law et al. with regard to muscle pain in the anterior tibialis, ${ }^{44}$ and dental journals, ${ }^{41}$ but not with statistical significance. It has been reported that females have a lower threshold of dental thermal pain onset and tolerance, ${ }^{45}$ and that females seek medical care more often than males ${ }^{46}$ suggesting that their report of pain could be inflated. More research is necessary to develop a more concrete clinical connection between the female gender and referred pain, and its associated etiology.

In terms of the remaining biographical information that was collected as a part of this investigation, the distribution of the different genders, races/ethnicities, and age were similar to those of Monongalia County, WV. This indicates an absence of bias and suggests that the data put forth in this study properly represents the population of the area.

Within the data, there was found to be a substantially larger number of molars causing referred pain than premolars and anterior teeth (Figure 15). As a result, the heat maps of maxillary and mandibular molars hold more validity and power. Future studies should focus on expanding the referral locations of maxillary and mandibular premolars and anterior teeth, using a larger number of subjects. This study displays that pain referral, however unlikely, can occur in those sextants and it would be an invaluable educational tool and reference to have an established and statistically significant referral pattern.

As mentioned in the results, there was a larger effect (statistically significant) on patients' activity, sleep, mood, and stress when the odontogenic pain was referred. This was likely due to the fact that the subject had to deal with multiple areas of pain, rather than just a single area. 
One could hypothesize that multiple areas of pain would be more difficult to control with overthe-counter medication, or more difficult to ignore, than just a single area.

Multiple areas of pain could refer to locations such as the forehead, temple, neck or ear, making the patient potentially concerned that something other than a toothache was the cause. This could add a psychological component to the patient's pain that would increase the stress, thereby affecting the sleep schedule, mood, and activity throughout the day. Additionally, if a subject is experiencing referred pain, they may see a different physician, such as an ENT or neurologist first, before seeing a dentist. This could cause the pain to escalate before receiving treatment and therefore, the subjects' activity, sleep, mood, and stress levels would be more exacerbated. A common example is the patient with referred pain originating from a mandibular molar. Per Figure 19, the most common referral site for a mandibular molar is the ipsilateral ear and therefore, a patient may be likely to see an ENT physician to address the issue before seeing a dentist.

\section{$\underline{\text { VI. Conclusions }}$}

- A pulpal diagnosis of irreversible pulpitis has a greater association with the presence of referred odontogenic pain than any other pulpal diagnosis.

- Females are more likely to experience referred pain of odontogenic origin than males, and to have that pain affect day-to-day life.

- Odontogenic referred pain within each sextant can refer to multiple different locations.

- Referred pain has a greater effect on subjects' activity, sleep, mood, and stress, and may require an interprofessional approach to treatment 
- Dental professionals can utilize the trends and results yielded from this investigation to further their understanding of referred odontogenic pain, allowing patients with referred pain to be more efficiently and accurately treated.

- Referred dental pain trends provided in this study can be a useful instructional tool in the dental curriculum.

\section{Future research}

- Recruit more patients to develop a statistically significant referral pattern for each dental sextant.

- Only survey patients with odontogenic referred pain originating from a maxillary or mandibular premolar or anterior tooth. Create an improved heat map for those areas.

- Recruit patients with referred pain and a diagnosis of pulpal necrosis who elect for the tooth to be extracted. Section and histologically evaluate the pulp/pulp space of those teeth and determine if they have any amount of vitality remaining.

- Further evaluate the connection between the female gender and referred odontogenic pain. 


\section{References}

1. Berman LH, Hargreaves KM. The Core Science of Endodontics: Diagnosis. In: Cohen 's Pathways of the Pulp. 11th ed. ; 2016:30.

2. Mattscheck D, Law AS, Nixdorf DR. Diagnosis of Nonodontogenic Toothache. In: Cohen's Pathways of the Pulp. 11th ed. ; 2016:688-690.

3. Markman S, Khan J, Howard J. Elusive dental pain. Gen Dent. 2010;(March-April):e6267.

4. Chen YH, Tseng CC, Chao WY, Harn WM, Chung SF. Toothache with a multifactorial etiology: a case report. Endod Dent Traumatol. 1997;13(5):245-247.

5. Vecchiet L, Giamberardino MA. Referred Pain: Clinical Significance, Pathophysiology, and Treatment. Phys Med Rehabil Clin N Am. 1997;8(1):119-136.

6. Hashemipour MA, Borna R. Incidence and characteristics of acute referred orofacial pain caused by a posterior single tooth pulpitis in an Iranian population. Pain Pract. 2014;14(2):151-157.

7. Wright EF. Referred craniofacial pain patterns in patients with temporomandibular disorder. J Am Dent Assoc. 2000;131(9):1307-1315.

8. AAE. American Association of Endodontists Colleagues of Excellence: Endodontic Diagnosis. Colleagues Excell. 2013:1-8.

9. Travell J, Simons D. Myofascial Pain and Dysfunction: The Trigger Point Manual. Volume One. Baltimore, Md: Williams \& Wilkins; 1983.

10. Hulihan J. Ice cream headache. Br Med J. 1997;(314):1364. 
11. Clinic M. Ice Cream Headaches. https://www.mayoclinic.org/diseases-conditions/icecream-headaches/symptoms-causes/syc-20373733?p=1. Published 1998.

12. Valat JP, Genevay S, Marty M, Rozenberg S, Koes B. Sciatica. Best Pract Res Clin Rheumatol. 2010;24(2):241-252.

13. Fehrenbach, Herring. Illustrated Anatomy of the Head and Neck. Elsevier. 2012.

14. Reeh ES, ElDeeb ME. Referred pain of muscular origin resembling endodontic involvement: Case report. Oral Surgery, Oral Med Oral Pathol. 1991;71(2):223-227.

15. Kellgren J. Observations on referred pain arising from muscle. Clin Sci. 1938;(3):180.

16. Nel H. Myofascial pain-dysfunction syndrome. J Prosthet Dent. 1978;(40):438-441.

17. Bender I. Pulpal Pain Diagnosis-A Review 1. J Endod. 2000;26(3):175-179.

18. Murray GM. Referred Pain. J Appl Oral Sci. 2009;17:6.

19. Markman S. Referred pain. J New Jersey Dent Assoc. 2014;(Spring):26-29.

20. Kojima Y. Convergence patterns of afferent information from the temporomandibular joint and masseter muscle in the trigeminal subnucleus caudalis. Brain Res Bull. 1990;24(4):609-616.

21. Sessle BJ, Hu JW, Amano N, Zhong G. Convergence of cutaneous, tooth pulp, visceral, neck and muscle afferents onto nociceptive and non-nociceptive neurones in trigeminal subnucleus caudalis (medullary dorsal horn) and its implications for referred pain. Pain. 1986;27(2):219-235. 
22. Aizenman C. Neuroscience in Action: Understanding our Brains and Nervous system. https://canvas.brown.edu/courses/851434/pages/neural-circuits. Published 2014.

23. Glick D. Locating Referred Pulpal Pains. Oral Surgery, Oral Med Oral Pathol. 1962;(15):613-623.

24. Ohara K, Shimizu K, Matsuura S, Ogiso B, Omagari D, Asano M, Tsuboi Y, Shinoda M, Iwata K. Toll-like receptor 4 signaling in trigeminal ganglion neurons contributes tonguereferred pain associated with tooth pulp inflammation. J Neuroinflammation. 2013;10:110.

25. Van Hassel H, Harrington G. Localization of pulpal sensation. Oral Surgery, Oral Med Oral Pathol. 1969;28(5):753-760.

26. Falace D, Reid K, Rayens M. The influence of deep (odontogenic) pain intensity, quality, and duration on the incidence and characteristics of referred orofacial pain. J Orofac Pain. 1996;10(3):232-239.

27. Friend L, Glenwright $\mathrm{H}$. An experimental investigation into the localization of pain from the dental pulp. Oral Surgery, Oral Med Oral Pathol. 1968;(25):765.

28. Chen E, Abbott PV. Dental Pulp Testing: A Review. Int J Dent. 2009;2009(iii):1-12.

29. Byers M, Maeda T. Periodontal Innervation: regional specializations, ultrastructure, cytochemistry and tissue interactions. Acta Med Dentium Helv. 1997;(2):116-133.

30. Abbott PV, Yu C. A clinical classification of the status of the pulp and the root canal system. Aust Dent J. 2007;52(1 SUPPL.):17-31.

31. Jafarzadeh H, Abbott PV. Review of pulp sensibility tests. Part I: general information and 
thermal tests. Int Endod J. 2010;43(9):738-762.

32. Jafarzadeh H, Abbott PV. Review of pulp sensibility tests. Part II: Electric pulp tests and test cavities. Int Endod J. 2010;43(11):945-958.

33. Newton CW, Hoen MM, Goodis HE, Johnson BR, McClanahan SB. Identify and Determine the Metrics, Hierarchy, and Predictive Value of All the Parameters and/or Methods Used During Endodontic Diagnosis. J Endod. 2009;35(12):1635-1644.

34. Levin LG, Law AS, Holland GR, Abbott PV, Roda RS. Identify and Define All Diagnostic Terms for Pulpal Health and Disease States. J Endod. 2009;35(12):1645-1657.

35. Gutmann JL, Hartwell GR, Gluskin AH, Baumgartner JC, Walton RE. Identify and Define All Diagnostic Terms for Periapical/Periradicular Health and Disease States. J Endod. 2009;35(12):1658-1674.

36. Rosenberg PA, Schindler WG, Krell K V., Hicks ML, Davis SB. Identify the Endodontic Treatment Modalities. J Endod. 2009;35(12):1675-1694.

37. Busti A, Kellogg D. Evidence-Based Medicine Consult. Dermatomes of the Face. https://www.ebmconsult.com/articles/anatomy-dermatomes-face. Published 2015.

38. Wright EF, Gullickson DC. Identifying acute pulpalgia as a factor in TMD pain. $J A m$ Dent Assoc. 1996;127(6):773-780.

39. Gauns SV, Gurudut PV. A randomized controlled trial to study the effect of gross myofascial release on mechanical neck pain referred to upper limb. Int J Health Sci. 2018;12(5):51-59. 
40. Sakamoto J, Morimoto Y, Ishii S, Nakano J, Manabe Y, Okita M, Tsurumoto T. Investigation and Macroscopic Anatomical Study of Referred Pain in Patients with Hip Disease. J Phys Ther Sci. 2014;26(2):203-208.

41. Brandão S, Suazo Galdames I, Guimarães AS, Marie SN. Referred Dental Pain, an Analysis of their Prevalence and Clinical Implication. Int J Odontostomatol. 2012;6(2):169-173.

42. Polomano RC, Galloway KT, Kent ML, Brandon-Edwards H, Kwon KN, Morales C, Buckenmaier C. Psychometric testing of the defense and veterans pain rating scale (DVPRS): A new pain scale for military population. Pain Med. 2016;17(8):1505-1519.

43. Jespersen JJ, Hellstein J, Williamson A, Johnson WT, Qian F. Evaluation of Dental Pulp Sensibility Tests in a Clinical Setting. J Endod. 2014;40(3):351-354.

44. Law L, McMullen T, Lee J, Sluka K, Graven-Nielsen T. More women than men experience referred pain in an experimental model of muscle pain. J Pain. 2008;9(4):9.

45. Edwards R, Fillingim R, Yamauchi S, Sigurdsson A, Buntin S, Mohorn SG, Maixner W. Effects of gender and acute dental pain on thermal pain responses. Clin J Pain. 1999;15(3):233-237.

46. Thompson AE, Anisimowicz Y, Miedema B, Hogg W, Wodchis WP, Aubrey-Bassler K. The influence of gender and other patient characteristics on health care-seeking behaviour: A QUALICOPC study. BMC Fam Pract. 2016;17(1):1-7. 


\section{Appendix A}

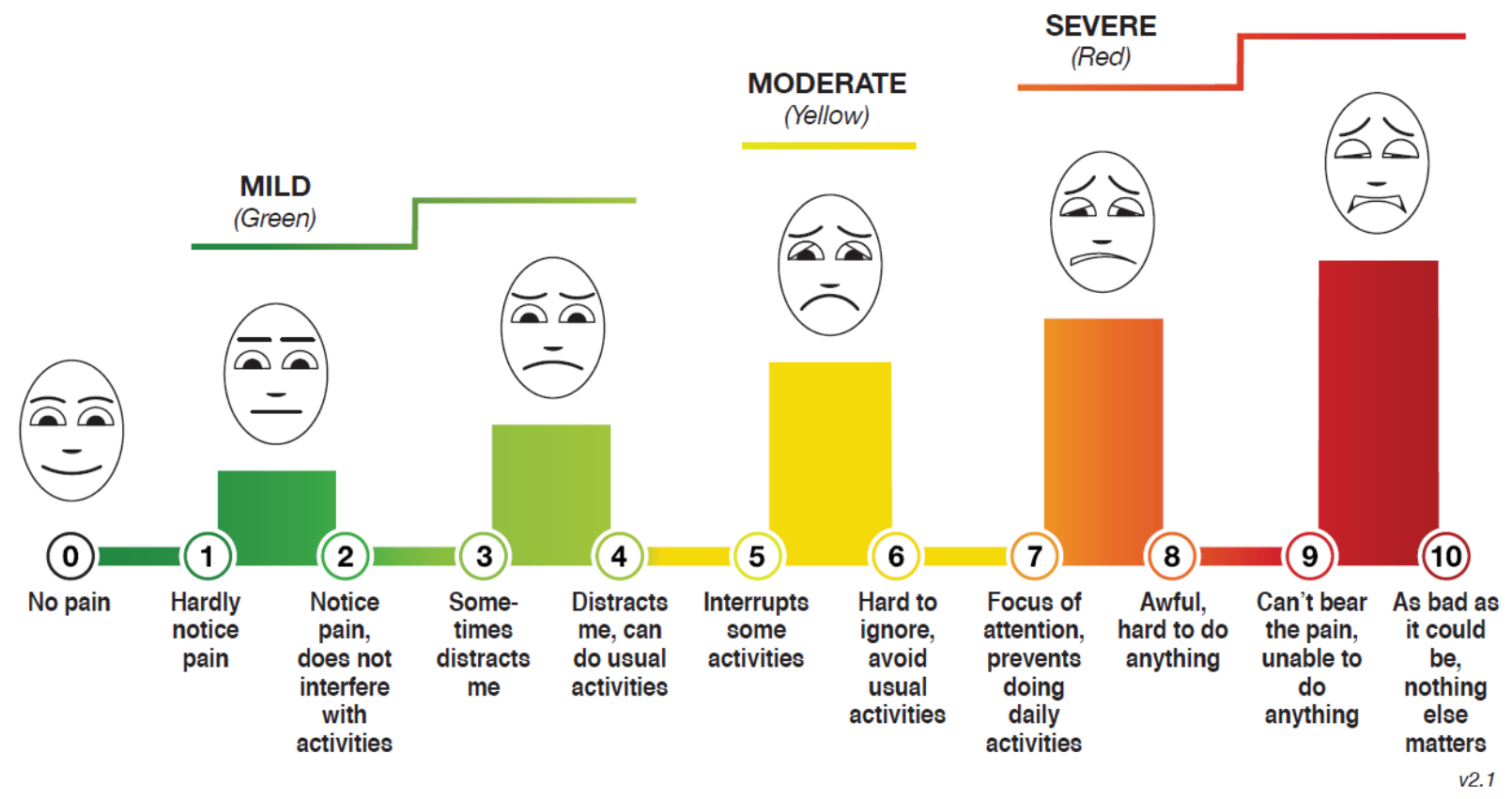

1. Circle the one number that describes how, during the past 24 hours, pain has interfered with your usual ACTIVITY:

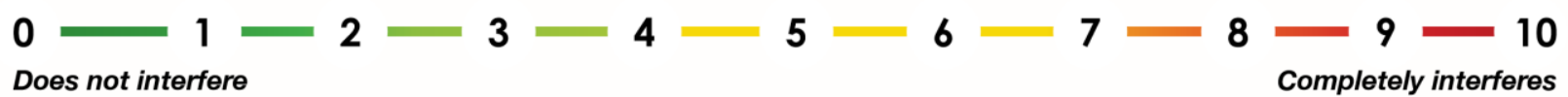

2. Circle the one number that describes how, during the past 24 hours, pain has interfered with your SLEEP:
$0=12$
$2=3$
$3=4$
$4=5=6$
$6=7$
$7=8$
$8=9-10$
Does not interfere
Completely interferes

3. Circle the one number that describes how, during the past 24 hours, pain has affected your MOOD:

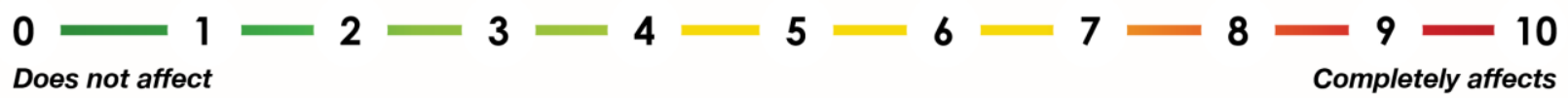

4. Circle the one number that describes how, during the past 24 hours, pain has contributed to your STRESS:

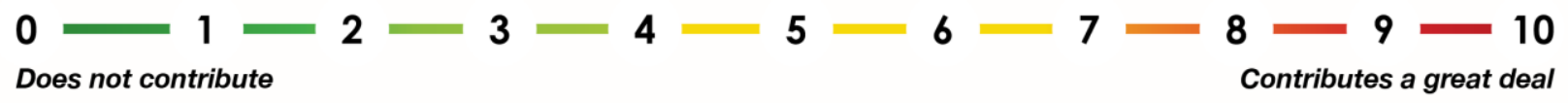

${ }^{*}$ Reference for pain interference: Cleeland CS, Ryan KM. Pain assessment: global use of the Brief Pain Inventory. Ann Acad Med Singapore 23(2): 129-138, 1994. V2.1 